Subscriber access provided by Lib4RI - Library for Eawag, Empa, PSI \& WSL

\title{
Article
}

\section{Simulation of Calcium Phosphate Species in Aqueous Solution: Force Field Derivation}

Raffaella Demichelis, Natalya A Garcia, Paolo Raiteri, Riccardo

Innocenti Malini, Colin L Freeman, John H. Harding, and Julian D Gale

J. Phys. Chem. B, Just Accepted Manuscript • DOI: 10.1021/acs.jpcb.7b10697 • Publication Date (Web): 12 Dec 2017

Downloaded from http://pubs.acs.org on January 18, 2018

\section{Just Accepted}

"Just Accepted" manuscripts have been peer-reviewed and accepted for publication. They are posted online prior to technical editing, formatting for publication and author proofing. The American Chemical Society provides "Just Accepted" as a free service to the research community to expedite the dissemination of scientific material as soon as possible after acceptance. "Just Accepted" manuscripts appear in full in PDF format accompanied by an HTML abstract. "Just Accepted" manuscripts have been fully peer reviewed, but should not be considered the official version of record. They are accessible to all readers and citable by the Digital Object Identifier (DOI囚). "Just Accepted" is an optional service offered to authors. Therefore, the "Just Accepted" Web site may not include all articles that will be published in the journal. After a manuscript is technically edited and formatted, it will be removed from the "Just Accepted" Web site and published as an ASAP article. Note that technical editing may introduce minor changes to the manuscript text and/or graphics which could affect content, and all legal disclaimers and ethical guidelines that apply to the journal pertain. ACS cannot be held responsible for errors or consequences arising from the use of information contained in these "Just Accepted" manuscripts. 


\title{
Simulation of Calcium Phosphate Species in
}

\section{Aqueous Solution: Force Field Derivation}

\author{
Raffaella Demichelis, ${ }^{1 *}$ Natalya A. Garcia, ${ }^{1}$ Paolo Raiteri, ${ }^{1}$ Riccardo Innocenti Malini, ${ }^{2,3}$ Colin \\ L. Freeman, ${ }^{2}$ John H. Harding ${ }^{2}$ and Julian D. Gale ${ }^{1}$ \\ ${ }^{1}$ Curtin Institute for Computation, The Institute for Geoscience Research (TIGeR) and \\ Department of Chemistry, Curtin University, PO Box U1987, Perth, WA 6845, Australia. \\ ${ }^{2}$ Department of Materials Science and Engineering, University of Sheffield, Sheffield, S1 3JD, \\ United Kingdom. \\ ${ }^{3}$ Laboratory for Biomimetic Membranes and Textiles, Empa, Swiss Federal Laboratories for \\ Materials Science Technology, St. Gallen 9014, Switzerland. \\ *raffaella.demichelis@curtin.edu.au
}




\begin{abstract}
A new force field has been derived for the aqueous calcium phosphate system that aims to reproduce the key thermodynamic properties of the system, including free energies of hydration of the ions and the solubility of the solid mineral phases. Interactions of three phosphate anions $\left(\mathrm{PO}_{4}{ }^{3-}, \mathrm{HPO}_{4}{ }^{2-}\right.$ and $\left.\mathrm{H}_{2} \mathrm{PO}_{4}{ }^{-}\right)$with water were calibrated through comparison with the results obtained from ab initio molecular dynamics using both GGA and hybrid density functional theory with dispersion corrections. In the solid state, the force field has been evaluated by benchmarking against experiment and other existing models and is shown to reproduce the structural and mechanical properties well, despite the primary focus being on thermodynamics. To validate the force field, the thermodynamics of ion pairing for calcium phosphate species in water has been computed and shown to be in excellent agreement with experimental data.
\end{abstract}




\section{INTRODUCTION}

Biomineralization is an important process both in the environment and within living systems, including the human body. It is responsible for the production of fine-tuned structures, from the mineral support for coral reefs through to the formation of protective shells and grinding tools. Therefore, understanding how biological systems can manipulate minerals into complex assembles is both of fundamental importance and offers the possibility to develop new strategies for biomimetic material synthesis.

Before we can begin to elucidate the pathways by which organics may influence mineral nucleation and growth, it is necessary to understand how such reactions occur in aqueous solution alone. While classical nucleation theory (CNT) has often been invoked to explain the early stages of mineral formation, there has recently been a re-examination of the process by which ions initially assemble, in light of results obtained for one of the most common biominerals, calcium carbonate. These suggest the possible existence of stable pre-nucleation clusters, ${ }^{1}$ in contrast to the initial formation of unstable nuclei through fluctuations below some critical size predicted in CNT. In the case of calcium carbonate it has been proposed that ion association occurs beyond ion pairs to form dynamic ionic polymers known as DOLLOP, ${ }^{2}$ which may ultimately undergo a liquid-liquid phase separation as concentration rises, representing the first nucleation event. ${ }^{3}$

As a result of the debate regarding pre-nucleation clusters for the case of calcium carbonate, this has raised the question as to whether analogous processes could occur for other common biomineral systems. Naturally attention has turned to the case of calcium phosphate solutions, with a particular focus on hydroxyapatite as it is a component of bones and tooth enamel. In contrast to calcium carbonate, the existence of stable species beyond ion pairs for calcium 
phosphate has been proposed for some time in the form of the so-called Posner's cluster, $\mathrm{Ca}_{9}\left(\mathrm{PO}_{4}\right)_{6},{ }^{4}$ which is believed to be a precursor to the formation of amorphous calcium phosphate. Evidence from atomic force microscopy indicates that Posner's clusters can be formed in the absence of organic species and so may be relevant to both biomineralisation and abiotic processes. ${ }^{5}$

Recently Habraken et $a l .{ }^{6}$ performed an extensive study of the initial stages of the association of calcium and phosphate ions using a range of techniques including cryo-TEM, infra-red spectroscopy, and wide-angle X-ray spectroscopy. Here, they proposed that the initial specie to be formed beyond ion pairing is $\mathrm{Ca}\left(\mathrm{HPO}_{4}\right)_{3}{ }^{4-}$, which then forms fractal assemblies through hydrogen bonding of multiple clusters. In addition, throughout the process, there are other equilibria involving proton transfer and calcium ion binding, as would be expected for such an environment. Indeed, it was proposed that the single calcium unit, $\mathrm{Ca}\left(\mathrm{HPO}_{4}\right)_{3}^{4-}$, is a soluble prenucleation species, that binds an additional calcium ion to yield $\mathrm{Ca}_{2}\left(\mathrm{HPO}_{4}\right)_{3}{ }^{2-}$ once the solubility of amorphous calcium phosphate is reached, thereby leading to nucleation. A subsequent study by Zhang et $a l^{7}$ claims to have identified species in which calcium is coordinated by two bidentate phosphate ions, as well as two further monodentate ligands, which can be either water or further phosphate anions, on the basis of XANES using synchrotron radiation. Given the challenges concerning the sensitivity of this approach it may be that the solution species observed could correspond to a later stage of the development of the speciation at high concentrations.

Although a considerable amount of data has been gathered from the application of experimental techniques to study pre-nucleation clusters, it has to be recognized that the interpretation of the results at the atomic level can be difficult for very small species. Hence the 
use of computer simulation is a valuable complement to the experimental information that is available. To date there have been several theoretical calculations performed that are relevant to calcium phosphate cluster formation. The structure and thermodynamics of the Posner's clusters and other related species have been extensively examined in a series of papers by Treboux and co-workers. ${ }^{8,9}$ Here the calculations were performed using ab initio methods, though all were based on clusters in vacuo and so the thermodynamic information has limited applicability to aqueous solution. Habraken et al. used ab initio calculations with explicit inclusion of some water molecules, along with a continuum description of the remaining solvation environment, to verify the size of their proposed species. However, the thermodynamic stability of the species was not considered.

Because of the complexity and dynamic nature of ion solvation it is a challenging undertaking to consider ion association in aqueous solution using first principles techniques. One such study, recently published, attempted to examine calcium phosphate pre-nucleation clusters using $a b$ initio molecular dynamics. ${ }^{10}$ Their results suggest that the $\mathrm{Ca}\left(\mathrm{HPO}_{4}\right)_{3}{ }^{4-}$ cluster is energetically more stable than the mono- or di-phosphate cluster. However, because the simulations were limited to 60 ps of unbiased dynamics, plus 5 ps of sample data for the umbrellas along a single reaction coordinate, the distance between the phosphate and the calcium ions, convergence of the thermodynamic properties is unlikely given that this is below the timescale of water exchange within the calcium ions coordination shell and the results may be significantly influenced by the initial configurations. The majority of studies have employed, instead, either force field methods or a hybrid approach to examine such processes to ensure adequate sampling. To the best of our knowledge, Zahn ${ }^{11}$ carried out the earliest study of calcium phosphate binding in aqueous solution, though the binding of calcium to phosphate groups of organic molecules has been 
studied for a longer time. ${ }^{12}$ The work of Zahn combined in vacuo quantum mechanical information on proton transfer energies with a classical force field to examine the speciation. He proposed that the $\mathrm{Ca}_{2}\left(\mathrm{PO}_{4}\right)^{+}$complex was the initial stable species, in contrast to the clusters later proposed by Habraken et al. Subsequent studies from this group have gone on to consider the association of calcium and phosphate ions with biomolecules. ${ }^{13}$ Recently $\mathrm{Ma}^{14}$ has simulated the association of calcium and phosphate ions with collagen using molecular dynamics based on the CHARMM force field. ${ }^{15}$ This work also proposes that a number of different species are present in highly concentrated solutions, based on observation using unbiased dynamics. However, the thermodynamics of these clusters was not quantified and the accuracy of the CHARMM force field for this specific system was not validated before the simulations were performed.

Given the significance of calcium phosphate association to biomineralization, the aim of the present work is to study the thermodynamics of the ion association processes in water using force field methods. In order to do this, it is necessary to have a force field that has been calibrated against the known experimental thermodynamics; something that has often been overlooked in the past for simulations of mineral nucleation. Here we follow a similar approach to that taken for calcium carbonate ${ }^{16,17}$ in order to derive a compatible force field model for the aqueous calcium phosphate system. This study is divided into two papers. In the first part, the derivation of the force field will be described along with the benchmarking of the results for the ions in solution and the corresponding solid phases, as well as simple ion pairing. In the second part, the thermodynamics of ion association processes in water will be determined in order to examine the hypothesis of Habraken et al and to contrast this with other possible pathways.

\section{METHODS}


The aim of the first part of this study is to develop a force field that can describe the thermodynamics of crystallization for minerals containing calcium phosphate from aqueous solution as accurately as possible within the limitations of a classical model. To achieve this, it is necessary to perform calculations on both the solid phases and ions in solution. These two scenarios are best described by different techniques, namely lattice dynamics and molecular dynamics, respectively. We will give the technical details for both methods as they pertain to the present study, followed by a summary of the strategy for parameterizing the force field.

\section{1) Lattice dynamics}

All lattice dynamics calculations in this work were performed using the GULP software. ${ }^{18}$ The energy, forces and second derivatives are evaluated analytically for the force field for either 3-D (solids) or 2-D (surfaces) periodic boundary conditions. For the electrostatics, the conditionally convergent sums are evaluated using either an Ewald or a Parry sum, for 3- and 2-D calculations, respectively, with a specified precision of 12 significant figures. The cut-off for the pairwise interactions was set at $9 \AA$ using a taper function to smooth the truncation over the last $3 \AA$, as for the corresponding potentials developed for calcium carbonate. ${ }^{19}$ Phosphate anions were treated as molecular fragments with a fixed connectivity and Coulomb subtraction of the intramolecular contribution. Interactions within the phosphates were modelled using a molecular mechanics approach with harmonic bond stretching and angle bending potentials. For phosphate anions that contain hydroxyl groups, a torsional potential has been specified for the H-O-P-O dihedral angle. Bond-bond cross terms were also considered for the O-P-O angles in phosphate in order to better describe coupling between the stretching modes in the vibrational spectra. 
Intermolecular interactions were treated using a combination of Buckingham and Lennard-Jones potentials.

\section{2) Molecular dynamics}

Both classical and $a b$ initio molecular dynamics simulations were used in this work. For classical molecular dynamics, the LAMMPS ${ }^{20}$ software was used. Here the real-space cut-offs and tapering is performed as for the lattice dynamics calculations. The main difference is that the electrostatic contribution is evaluated using the Smoothed Particle Mesh Ewald technique in order to increase the efficiency for large systems.

All classical simulations were run using a time step of 1 fs and a Nosé-Hoover thermostat and barostat within the isothermal-isobaric ensemble for a cubic box of 4,173 water molecules (corresponding to a cell length of $49.843 \AA$ ). Free energy perturbation ${ }^{21}$ and multiple-walkers ${ }^{22}$ well-tempered metadynamics ${ }^{23}$ were adopted to explore the solvation free energy of the ions and the free energy profile of the calcium-phosphate ion pair, respectively.

Free energy perturbation was run at different temperatures by progressively switching off the electrostatic and van der Waals' interactions between the ions and water (20 equally-spaced stages of $5 \mathrm{~ns}$ each per interaction, with 500 ps equilibration). The calculated hydration free energy was then corrected for finite size effects. ${ }^{24}$ The simulations were run at different temperatures, and for every temperature the calculations were repeated 3 times starting from different configurations. The results of these runs were then averaged to obtain the final value. Metadynamics calculations were performed using the PLUMED 2.0 plug-in. $^{25}$ The collective variables chosen were the calcium-phosphorus distance and the coordination number of calcium with respect to the oxygen atoms of water. The Gaussian widths were set to $0.2 \AA$ and 0.1 , 
respectively. Gaussians were deposited every 1 ps with an initial height of $k_{B} T$. We have used 30 parallel walkers for a total simulation time of about $300 \mathrm{~ns}$, and a bias factor of 5 to progressively reduce the heights of the Gaussians until convergence within the well-tempered algorithm.

$A b$ initio molecular dynamics was performed using the program $\mathrm{CP} 2 \mathrm{~K}^{26}$ with the PBE-D3 functional based on the Gaussian planewave approach. ${ }^{27}$ The core electrons and nuclei were described using the GTH pseudopotential ${ }^{28}$ with valence basis sets of TZ2P quality. The electron density was described with a planewave cut-off of $300 \mathrm{Ry}$, while the self-consistent field calculation was performed using the orbital transformation algorithm. ${ }^{29}$ All the species considered were placed in separate cubic cells with a dimension of $14.3 \AA$ containing 99 water molecules. Simulations were run for up to $37 \mathrm{ps}$ in the NVT ensemble using a time step of $0.5 \mathrm{fs}$. Here an elevated temperature of $330 \mathrm{~K}$ was used to offset the known systematic over-structuring of water for the density functional used, even with the inclusion of empirical dispersion corrections ${ }^{30,31}$ As a further validation, up to $10 \mathrm{ps}$ of $a b$ initio dynamics has also been performed using a hybrid PBE0-D3 functional, except with 50\% Hartree-Fock (HF) exchange, starting from the final configuration of the PBE-D3 run. These simulations were used to examine the sensitivity of the results to electron localization, which is known to be influenced by the inclusion of HF exchange. ${ }^{32}$ The hybrid functional calculations were accelerated by using the auxiliary density matrix method ${ }^{32}$ with the pFIT3 auxiliary basis set.

\section{PARAMETERIZATION \\ When approaching the parameterization of a force field suited to modelling the nucleation and growth of calcium phosphate materials, it was decided to build on our previous work for the}


aqueous calcium carbonate system to ensure compatibility of both parameter sets ${ }^{17}$ This places a number of constraints on the present fitting procedure. Firstly, the choice of water model should be $\mathrm{SPC} / \mathrm{Fw}^{33}{ }^{33}$ a simple point charge, flexible representation. Given that other water models were previously used for the aqueous calcium carbonate case, including rigid ones, without substantially affecting the ability of the fit to reproduce key experimental quantities, it seems likely that the constraint of using SPC/Fw should not be a particular issue. Secondly, the overall charges of cations and anions must equal the formal ionic charge. Again, this represents a natural choice and simplifies the simulation of both solids and solutions of different compositions while maintaining charge balance. Thirdly, and finally, the interaction of $\mathrm{Ca}^{2+}$ ions with water must retain the same parameters as the previous model. Since this interaction is fitted to the solvation free energy of the calcium cation in water, it is largely independent of whether the corresponding anion is phosphate or carbonate, except for the constraint that the total thermodynamics for mineral solubility should agree with experiment. To this extent, the partitioning of the total free energy of solvation for the ions into individual contributions does link the cation and anion parameterizations, along with the lattice free energy. However, there is no reason at this stage to believe that the existing choice of the calcium free energy of solvation will adversely affect the parameterization for phosphate solvation.

In order to study the solution speciation of phosphate in water it is necessary to consider the three possible anions; phosphate $\left(\mathrm{PO}_{4}{ }^{3-}\right)$, hydrogen phosphate $\left(\mathrm{HPO}_{4}{ }^{2-}\right)$ and dihydrogen phosphate $\left(\mathrm{H}_{2} \mathrm{PO}_{4}^{-}\right)$. The $\mathrm{pK}_{\mathrm{a}}$ values for hydrogen and dihydrogen phosphate are 12.32 and 7.21, respectively. ${ }^{34}$ The parent species, phosphoric acid, has a $\mathrm{pK}_{\mathrm{a}}$ of 2.16 and is therefore unlikely to play a role in the crystallization process under conditions relevant to biomineralization. Hence, we have not considered this species in the present work. Similarly, the phosphate anion will only 
have a substantial concentration under very alkaline conditions and so has a limited role in aqueous solutions relevant to the current work. However, as assemblies of ions begin to form, the pKa value of hydrogen phosphate contained within such species will decrease, with phosphate becoming increasingly relevant.

\section{1) Intramolecular interactions}

The starting point for the parameterization procedure was to obtain a model for the intramolecular potentials of the (hydrogen-)phosphate anions. To do this ab initio quantum mechanical calculations were initially performed on the isolated anions at the M06/6-311++G** level of theory using the Q-Chem program. ${ }^{35}$ An initial set of force constants was derived using the vibrational frequencies obtained from these calculations. To ensure that the modes were correctly assigned, the eigenvectors computed with the force field were projected onto the quantum mechanical equivalents at every step of the least squares fitting procedure. It is important to note that the highly-charged phosphate anions are unstable in vacuum with respect to ionization, and the excess electrons only remain localized on the species due to the finite atom-centered basis set. However, the point of this step was not to obtain accurate physically meaningful results, but purely to obtain an initial reasonable estimate of the force constants for subsequent refinement against other properties. In order to determine starting values for the intramolecular equilibrium geometry, the anions were again also optimized at the M06/6$31+\mathrm{G}^{* *}$ level of theory in the presence of the SM8 solvent model ${ }^{36}$ using the dielectric constant of water. Subsequently the $r_{0}$ values were adjusted to provide a compromise between the appropriate bond length in solution and in the solid-phases. 
The intramolecular force field terms involve harmonic bond stretching and angle bending. For those anions with a hydroxyl group, a torsional interaction between the hydrogen and other oxygen atoms was included. In addition, to improve the description of the vibrational properties, bond-bond and bond-angle coupling terms were also considered. The precise functional forms of the two-body $\left(U_{i j}\right)$, three-body $\left(U_{i j k}\right)$, and four-body $\left(U_{i j k l}\right)$ energies are given below;

$$
\begin{gathered}
U_{i j}=\frac{1}{2} k_{2}\left(r_{i j}-r_{0}\right)^{2} \\
U_{i j k}=\frac{1}{2} k_{3}^{\text {angle }}\left(\theta_{i j k}-\theta_{0}\right)^{2}+k_{3}^{\text {bond }- \text { bond }}\left(r_{i j}-r_{0 i j}\right)\left(r_{j k}-r_{0 j k}\right) \\
+k_{3}^{\text {bond-angle }}\left[\left(r_{i j}-r_{0 i j}\right)+\left(r_{j k}-r_{0 j k}\right)\right]\left(\theta_{i j k}-\theta_{0}\right) \\
U_{i j k l}=k_{4}^{\text {torsion }}(1-\cos (3 \phi))
\end{gathered}
$$

where $r_{i j}$ and $r_{j k}$ are the distances between atoms $i-j$ and $j-k$, respectively, $\theta_{i j k}$ is the angle between the bonds of the atoms bound to the pivot atom $j$, and $\phi$ is the torsion angle between $i-j$ and $k-l$ about the vector between $j$ and $k$. All equilibrium bond lengths and angles were constrained to be consistent between the harmonic and cross-terms. Intramolecular parameters for $\mathrm{PO}_{4}^{3-}, \mathrm{HPO}_{4}{ }^{2-}$ and $\mathrm{H}_{2} \mathrm{PO}_{4}^{-}$are reported in Table 1. Here, and in the remainder of this paper, oxygen atoms in $\mathrm{PO}_{4}^{3-}$ will be labelled as $\mathrm{O}$; the protonated oxygen atom(s) in $\mathrm{HPO}_{4}{ }^{2-}$ and in $\mathrm{H}_{2} \mathrm{PO}_{4}^{-}$will be labelled as $\mathrm{O} 8$ and $\mathrm{O} 10$, respectively; the other oxygen atoms in $\mathrm{HPO}_{4}{ }^{2-}$ and in $\mathrm{H}_{2} \mathrm{PO}_{4}^{-}$will be labelled as $\mathrm{O} 9$ and $\mathrm{O} 11$, respectively. The hydrogen atoms in $\mathrm{HPO}_{4}{ }^{2-}$ and $\mathrm{H}_{2} \mathrm{PO}_{4}{ }^{-}$ are labelled as $\mathrm{H} 8$ and $\mathrm{H} 10$, respectively; $\mathrm{P} 1$ is the phosphorus atom in both $\mathrm{PO}_{4}{ }^{3-}$ and $\mathrm{HPO}_{4}{ }^{2-}$, while $\mathrm{P} 2$ represents the phosphorus atom in $\mathrm{H}_{2} \mathrm{PO}_{4}^{-}$.

\section{2) Intermolecular interactions}


Intermolecular interactions were described using a combination of electrostatics and shortrange repulsions of both Buckingham and Lennard-Jones forms. The precise forms of the potentials are as implemented in the LAMMPS package ${ }^{20}$ and as follows, where (4) and (5) are both the standard 12-6 Lennard-Jones potential in epsilon/sigma form and A/B form and (6) is the standard Buckingham potential:

$$
\begin{gathered}
E(r)=4 \varepsilon_{l j}\left[\left(\frac{\sigma}{r_{l j}}\right)^{12}-\left(\frac{\sigma}{r_{l j}}\right)^{6}\right] \\
E(r)=\frac{A_{l j}}{r^{12}}-\frac{A_{l j}}{r^{6}} \\
E(r)=A_{b u c k} e^{\left(-r / \rho_{b u c k}\right)}-\frac{C_{b u c k}}{r^{6}}
\end{gathered}
$$

All Coulomb interactions are excluded within the phosphate anions. The charges used for the different species are $\mathrm{Ca}=+2.0, \mathrm{P} 1=+0.97, \mathrm{P} 2=+1.38, \mathrm{O} 7=-0.9925, \mathrm{O} 8=\mathrm{O} 10=-0.655, \mathrm{O} 9=\mathrm{O} 11=-$ 0.89 , and $\mathrm{H} 8=\mathrm{H} 10=+0.355$, all in atomic units. Initial values for the charges were taken from a Mulliken analysis of the phosphate ions within the solvent model. However, the final values were obtained by fitting against the solid phases, subject to the constraint that a given species must have the same charge in all environments. For water, the charges remain as for the original $\mathrm{SPC} / \mathrm{Fw}$ model $(\mathrm{H} 2=+0.41, \mathrm{O} 2=-0.82) .^{33}$

\subsection{1) Intermolecular interactions: water-phosphate}

To determine the intermolecular parameters between the phosphate anions and water a twostep process was used. Because the free energy of solvation represents a single number that results from several different contributions, it is hard to unambiguously determine the intermolecular potential parameters between the phosphate anions and water from this quantity 
alone. Therefore, in the initial phase of parameterization, ab initio calculations at the M06/6$311++\mathrm{G}^{* *}$ level $^{37}$ were used to compute binding configurations between water molecules and different edges of the phosphorus-oxygen tetrahedra. Fitting the hydrogen bonding distances between water and the two types of phosphate oxygen identified above separately provides information that discriminates between the relative solvation strength of different regions of the hydrogen phosphate and dihydrogen phosphate anions.

The geometry of the water coordination sphere obtained when running molecular dynamics was carefully checked, and parameters were readjusted in order to reproduce the correct water structure as suggested by Pegado et $a l . .^{38}$ as a result of an ab initio molecular dynamics investigation of sulfate anions (see Figure 1). The original parameters have also been adjusted by comparing the pair distribution functions obtained with the force field and those obtained from $a b$ initio simulations of the anions in aqueous solution (see section 2.2 and Figures S1, S2 and S3 in the Supporting Information).

Ultimately, the final refinement involved adjusting the Lennard-Jones and Buckingham interactions between water and the oxygen and hydrogen atoms of the phosphate anions in order to reproduce a target free energy of solvation. This was carried out using free energy perturbation, as described in section 2.2. After an initial calculation to determine the free energy of solvation for an anion with the starting parameters, refinement was performed by perturbing the previous estimated set of parameters. By reducing the magnitude of the perturbation, faster convergence of the free energy difference was achieved. The final water-phosphate force field parameters are reported in Table 2, together with the other intermolecular parameters (see next section). It is worth nothing that for the $\mathrm{H}_{2} \mathrm{PO}_{4}{ }^{2-}$ water parameter we overlaid a Lennard-Jones and a Buckingham potential for the $\mathrm{O} 2-\mathrm{O} 10$ pair. This was done to achieve a satisfactory 
agreement with the experimental solvation free energy and with the ab initio radial pair distribution functions (Figure S1).

Reference values for the targeted free energy are reported in Table 3 and compared to those obtained with our force field. Due to the lack of experimental data, the former has been obtained through ab initio electronic structure calculations at the M06/6-31G* level of theory combined with the SM8 implicit solvent model. Appropriate testing on the accuracy of the basis set was performed on $\mathrm{PO}_{4}{ }^{3-}$ : the results obtained with the $6-31+\mathrm{G}^{* *}$ basis set differed by $2.5 \mathrm{~kJ} / \mathrm{mol}$, which is within the uncertainty associated with the free energy perturbation.

A very limited set of estimates for the hydration free energy of phosphate anions is present in the literature, and they are all in disagreement by a few hundred $\mathrm{kJ} / \mathrm{mol}$, as shown in Table 3 . The first date back to 1970 , when George et al. ${ }^{39}$ provided heats of solvation through calculations based on previous experimental measurements. These values are in relative good agreement with the $\Delta \mathrm{H}$ of hydration obtained for $\mathrm{PO}_{4}{ }^{3-}$ and $\mathrm{HPO}_{4}{ }^{2-}$ with our force field, which was calculated by running the free energy perturbation at temperatures between $290 \mathrm{~K}$ and $330 \mathrm{~K}$ and then fitting the results, as shown in Figure 2. Years later, Marcus ${ }^{40}$ systematically derived the hydration entropy, enthalpy and free energy of a number of cations and anions, including the phosphate species, through an empirical model based on the assumption of spherical particles. Due to the approximations introduced in that model, both $\Delta \mathrm{H}$ and $\Delta \mathrm{G}$ of hydration for large and polyvalent anions are estimated to be 100 to $200 \mathrm{~kJ} / \mathrm{mol}$ too negative with respect to the real value. This is consistent with our $a b$ initio calculations and with other estimates. ${ }^{39,41,42}$ From the slope of the fitting performed in Figure 2 we have obtained the hydration entropies for the three phosphate species, which are in reasonable agreement with the values provided by Marcus. ${ }^{40}$ As a visual comparison, the experimental line is reported in Figure 2, arbitrarily set to cross the average of 
our calculated values at $300 \mathrm{~K}$, and with the slopes taken from Marcus' $\Delta \mathrm{S}$ values. Marcus provided a value for the entropy of hydration $\Delta \mathrm{S}\left(\mathrm{H}_{2} \mathrm{PO}_{4}{ }^{-}\right)$that was nearly identical to that of $\Delta \mathrm{S}\left(\mathrm{HPO}_{4}{ }^{2-}\right)$, whereas it should be expected to be higher and therefore closer to the calculated value.

The enthalpy of hydration, $\Delta \mathrm{H}\left(\mathrm{H}_{2} \mathrm{PO}_{4}^{-}\right)$, does not agree with George et al.'s estimate, ${ }^{39}$ even though the reference value for the free energy was obtained using the same methods as for the other phosphate species. To obtain an enthalpy of hydration that is comparable to the value of George et al. either the hydration entropy would have to be positive, or the starting free energy should be more endothermic by nearly a hundred $\mathrm{kJ} / \mathrm{mol}$. Both these scenarios would go against all the other experimental evidence, and so we assume that, given the magnitude of $\Delta \mathrm{H}_{(}\left(\mathrm{H}_{2} \mathrm{PO}_{4}\right)$, the experimental estimate could be subject to a larger error than for the other species.

Through $a b$ initio calculations embedded within a Langevin dipole scheme and comparison with solvation free energies estimated from either experimental gas phase basicity or proton affinity, Florian and Warshel $^{43}$ provided values for the free energies of hydration of the phosphate species that are about 50 to $250 \mathrm{~kJ} / \mathrm{mol}$ less negative than those calculated in this paper. Moser $^{42}$ also ran $a b$ initio calculations and explored a range of continuum solvation models, providing free energies of hydration that span a range of several hundred $\mathrm{kJ} / \mathrm{mol}$ (see Table 3). However, based on the experimental gas basicity and $\mathrm{pKa}$, he estimated the best values to be $-2296.2,-1077.8$ and $-332.6 \mathrm{~kJ} / \mathrm{mol}$ for $\mathrm{PO}_{4}{ }^{3-}, \mathrm{HPO}_{4}{ }^{2-}$, and $\mathrm{H}_{2} \mathrm{PO}_{4}{ }^{-}$, respectively. These values are 198, 62 and $6 \mathrm{~kJ} / \mathrm{mol}$ less negative than those calculated in this paper.

The reference values that we estimated through first principles calculations are at the most exothermic end of the range provided by previous experiments and calculations. However, these values provide the best compromise between the accuracy of the hydration free energy, the 
structure and properties of the solid phases, and the pairing free energy profile of the phosphate species with calcium in water (see next sections).

\subsection{2) Intermolecular interactions: calcium-phosphate}

The remaining terms to be fitted are the interactions between the calcium and phosphate ions. Here information from the solid state was used within lattice dynamics calculations as part of a relaxed fitting process. For example, observables included the crystallographic data for $\alpha$ $\mathrm{Ca}_{3}\left(\mathrm{PO}_{4}\right)_{2}$, monetite, brushite and monocalcium phosphate monohydrate, as well as bulk moduli, elastic constants and other mechanical properties, where available. Importantly, the quasiharmonic lattice free energy at $298.15 \mathrm{~K}$, relative to the free energy of the component ions in aqueous solution, was also used to fit the solubility of the materials, again where known. Despite the complexity of the structures of the phases, it was generally only possible to refine the $A$ parameter of the Buckingham potential for each calcium-phosphate interaction instead of both repulsive parameters. All the final intermolecular force field parameters are reported in Table 2.

\section{RESULTS AND DISCUSSION}

\section{1) Bulk properties of calcium phosphate minerals}

Before examining the results of the present work for bulk calcium phosphate minerals, it is important to note that other models for such systems do exist. One of the first lattice dynamics studies was that of Taylor et $a .^{44}$ who derived a rigid-ion force field for metal diphosphates, including that of calcium. Shortly afterwards Gale and Henson ${ }^{45}$ derived a shell model potential for framework aluminophosphates. Subsequently many different shell model force fields have 
been derived for apatite, ${ }^{46-48}$ though phosphate glasses have also been considered. ${ }^{49}$ Very recently a new rigid-ion force field has been derived for apatite with the aim of reproducing its surface properties at different $\mathrm{pH} .{ }^{50}$ However, free energies were again not explicitly considered during the derivation, which relies on combination rules for the interactions with water. For the purpose of comparison in this work we will give results for one example of a shell model force field, namely the one developed by Pedone et al., ${ }^{51}$ as well as for a rigid ion model, proposed by Hauptmann et al., ${ }^{52}$ alongside the new results.

\subsection{1) Tricalcium phosphate}

The first case to be considered for the bulk mineral phases is tricalcium phosphate (TCP, $\left.\mathrm{Ca}_{3}\left(\mathrm{PO}_{4}\right)_{2}\right)$ since this contains the simplest anion, $\mathrm{PO}_{4}{ }^{3-}$, with a tetrahedral geometry and a single unique oxygen type. TCP is used in a wide range of applications due to its biocompatibility. Despite this, the properties of this substance are far less well characterized than those of other calcium phosphate compounds, such as the apatite family of minerals. Three polymorphs exist as a function of temperature, which are labelled $\alpha, \alpha^{\prime}$ and $\beta$. At high pressures, an additional phase can form, $\gamma$, which is known as tuite. Of the low-pressure forms, the $\beta$ polymorph is known to be the most stable below $1398 \mathrm{~K}$, beyond which it transforms to the $\alpha$ and then $\alpha$ ' structures before melting. ${ }^{53}$ Unfortunately, from the point of view of potential derivation, the most stable phase contains a partially occupied Ca site and so is disordered.$^{54}$ Therefore for the purposes of fitting we have used the monoclinic structure of the high temperature $\alpha$ polymorph that contains 24 formula units per cell..$^{55}$

For force field parameterization it is desirable to include more than just the structure in the fitting process, even for materials, such as $\alpha$-TCP, that have a complex, low symmetry atomic 
arrangement. However, the only information available on the mechanical properties for the phases of tricalcium phosphate was obtained from $a b$ initio calculations. Based on these properties and the structure of the different phases, the interaction parameters between $\mathrm{Ca}^{2+}$ and $\mathrm{PO}_{4}{ }^{3-}$ were derived. Results for the structure and properties of the tricalcium phosphate phases are given in Tables 4-6.

Considering the structural results for $\alpha$-TCP as the fitted structure, all of the force fields examined provide a reasonable description. The shell model of Pedone et al yields the best volume with a value that is too small by $0.6 \%$ due to a partial cancellation of errors between the $a$ and $b$ cell parameters that underestimate and overestimate, respectively, the experimental values. The rigid ion model of Hauptmann et al has a similar functional form to the present work, but the parameters that have been transferred from apatite give the largest volume error. This exceeds $3 \%$ due to a systematic overestimation of all cell dimensions. Our new rigid ion force field also overshoots the experimental cell volume by $1.9 \%$, but nearly all of the discrepancy is concentrated in the $b$ cell parameter.

The lack of accessible experimental data for mechanical properties at ambient conditions makes it more difficult to assess the quality of the force field results. The work of Liang et al. ${ }^{56}$ provided a comprehensive study of the mechanical properties of both $\alpha$-TCP and $\beta$-TCP using Kohn-Sham density functional theory based on the PBE functional, though this would be expected to underestimate the stiffness of the material. Here DFT, shell model and the current rigid ion force field results are all in reasonable agreement for the bulk and shear moduli, while surprisingly, the force field of Hauptmann et al. gives a mechanically stiffer description of the system even though the volume is overestimated. Similar trends are found for the on-diagonal elastic constants. Although few definite conclusions can be drawn, it appears likely that the force 
field developed in this work does a reasonable job in capturing the mechanical properties within the limits of a rigid ion model. However, the primary objective is to develop a model that is appropriate for thermodynamics.

A further test of the force field models is offered by the structure of the high-pressure phase of TCP, tuite. Here the experimental sample is typically subjected to an excess of $12 \mathrm{GPa}$ of pressure to form this phase and then quenched to ambient conditions. After optimizing $\gamma$-TCP, the phonons were calculated at the Brillouin zone center as a first check on the dynamical stability of the structure. Imaginary phonons were observed for the present new force field (three modes) and that of Hauptmann et al. (seven modes) for the hexagonal R-centered unit cell. After removal of the phonon instabilities the structure remained hexagonal, but with a small rotation of the phosphate groups about the $c$ axis, leading to loss of mirror symmetry. It could be argued that these imaginary modes occur because the structure is generated at high pressure, though it can be quenched to ambient conditions. However, when optimized at $12 \mathrm{GPa}$, both the model of Hauptmann et al and our force field yield three imaginary modes. The same problem was not found to occur for the force field of Pedone et al., despite the tendency of shell models to favor lower symmetry structures if the polarizability is high enough. It appears that the distortion of the tuite structure is very sensitive to volume due to a set of degenerate modes with a frequency of only $9 \mathrm{~cm}^{-1}$ (based on the Pedone model) that become imaginary with a slight increase in the cell parameters. Based on our new force field, the energy reduction due to distortion is $\sim 0.5 \mathrm{~kJ} / \mathrm{mol}$ per formula unit and so rotation of the phosphate groups is likely to be quite dynamic, therefore averaging to the observed higher symmetry. The force field derived in the present work provides the most accurate lattice parameters of tuite at ambient pressure in comparison to experiment. 
Moreover, a recent study has given an experimental bulk modulus ${ }^{57}$ for benchmarking. Our new model provides the best agreement, closely followed by the model of Pedone et al.

The final polymorph of tricalcium phosphate to consider, whose structure is known, is the $\beta$ phase. In order to handle the fractional occupancy of the calcium sites, we can either employ a mean field description, in which all interactions are scaled by the product of the site occupancies, or construct an ordered model where half the calcium atoms on this site have been deleted. We have tested both approaches and they result in similar averaged structural parameters, but the thermodynamics of the ordered model are likely to be more reliable. Hence, we have adopted the latter approach. Of the six partially occupied sites there are three pairs of sites with the same fractional coordinates in the $x y$ plane. To remain close to the hexagonal symmetry of the cell we have removed one site from each pair separated by $1 / 3$ in fractional units along the $c$-axis. We have used this configuration to calculate structure and properties for $\beta$-TCP (Table 6). As with the mineral tuite, our new rigid ion force field provides the best description of the cell parameters and is comparable to the shell model in terms of giving reasonable mechanical properties. The experimental bulk modulus, which is underestimated by all calculations, comes from indentation measurements rather than from an equation of state. This may therefore lead to some intrinsic differences between the values.

Having performed calculations on three of the four known polymorphs of tricalcium phosphate, we are now in position to examine the relative phase stability of the materials. Two previous density functional theory studies both found that $\beta$-TCP is more stable than $\alpha$-TCP, as would be expected from the experimental phase diagram. Unfortunately, the prediction of the energy difference between these polymorphs appears to be challenging for force field methods since the three potential models examined suggest different orderings in the stability and none of 
them yield $\beta$-TCP as the ground state. The two rigid ion models predict that $\alpha$-TCP is more stable than $\beta$-TCP, whereas all other methods at least consistently give the inverse order. This indicates that polarization effects may play an important role in the energy difference between these two phases. Including the phonon contribution to the free energy fails to alter the order of stability.

\subsection{2) Monocalcium and Dicalcium phosphate}

The monocalcium (MCP) and dicalcium phosphates (DCP) differ from the preceding tricalcium materials in that they do not appear to exhibit polymorphism. Instead there is variability in the water content leading to two main phases for MCP and three for DCP. In the former case, an anhydrous and a monohydrate phase are known by the acronyms of MCPA $\left(\mathrm{Ca}\left(\mathrm{H}_{2} \mathrm{PO}_{4}\right)_{2}\right)$ and $\mathrm{MCPM}\left(\mathrm{Ca}\left(\mathrm{H}_{2} \mathrm{PO}_{4}\right)_{2} \cdot \mathrm{H}_{2} \mathrm{O}\right)$, respectively. In the latter case the three phases are monetite $\left(\mathrm{CaHPO}_{4}\right)$, brushite $\left(\mathrm{CaHPO}_{4} \cdot 2 \mathrm{H}_{2} \mathrm{O}\right)$ and a hemi-hydrate phase $\left(\mathrm{CaHPO}_{4} \cdot 1 / 2 \mathrm{H}_{2} \mathrm{O}\right)$. While MCP phases are relevant in the fertilizer industry, DCP finds application in biocompatible cements, and could be used as a proton conductor. ${ }^{58}$ Of all these compounds, the only ones observed in nature are monetite and brushite.

Monetite, as the anhydrous DCP, was chosen as the starting point for the derivation of the intermolecular potential involving the $\mathrm{HPO}_{4}^{2-}$ phosphate ion and the $\mathrm{Ca}^{2+}$ ion. The structure of this mineral undergoes a proton order-disorder transition just below ambient conditions and so we have chosen to focus on the low temperature ordered structure obtained from neutron refinement. ${ }^{59}$ Unfortunately, the single crystal mechanical properties of this phase are unknown and so there is only limited information to fit to. As a result, many of the parameters are held 
fixed during the refinement and initially only the repulsive interactions between the two types of oxygen in the phosphate group and $\mathrm{Ca}^{2+}$ are explicitly refined.

The results for monetite are presented in Table 7 alongside the experimental crystal structure and the percentage deviation of the optimized values. All the cell lengths are reproduced to within $1 \%$, while the deviations in the cell angles are not larger than $\sim 3 \%$ for the triclinic cell. The error in the volume corresponds to an overestimation by $1.3 \%$. Although there is nothing to compare against, the mechanical properties of monetite are in line with what might be expected from the TCP phases, with the presence of the hydroxyl group and lower charge on the phosphate anion making the system slightly softer. One property that has been measured for monetite on several occasions is the vibrational spectrum. Here the modes associated with the hydroxyl component of $\mathrm{HPO}_{4}{ }^{2-}$ can be identified, with the (P)OH stretching modes being at 2360, 2849, and $3190 \mathrm{~cm}^{-1}$, while the P-O-H bending modes give rise to broad peaks in the range 1300$1450 \mathrm{~cm}^{-1} \cdot{ }^{58}$ Using our force field model, the hydroxyl stretching modes are overestimated at $3540-3600 \mathrm{~cm}^{-1}$, even when allowing for significant red-shifting due to anharmonic corrections. Conversely the P-O-H bending modes are underestimated, lying in the range of $1190-1338 \mathrm{~cm}^{-1}$. Both of these errors reflect the fitting of the force constants for $\mathrm{HPO}_{4}{ }^{2-}$ using values for the isolated ion. Even with the anharmonic coupling terms, the change due to the solid-state environment fails to be captured.

The properties of monocalcium phosphate are arguably less well characterized than those of the other solid calcium phosphates. Both the anhydrous $\left(\mathrm{Ca}\left(\mathrm{H}_{2} \mathrm{PO}_{4}\right)_{2}, \mathrm{MCPA}\right)$ and monohydrate $\left(\mathrm{Ca}\left(\mathrm{H}_{2} \mathrm{PO}_{4}\right)_{2} \cdot \mathrm{H}_{2} \mathrm{O}, \mathrm{MCPM}\right)$ forms adopt triclinic crystal structures. ${ }^{60,61}$ When considering the solubility of these phases, it is important to note that MCPA is not believed to be a stable phase below $100^{\circ} \mathrm{C}^{62}$ and therefore we have to use MCPM to validate this property instead. Using the 
current force field we estimate the solubility $\left(-\log \left(K_{s p}\right)\right.$ at $\left.25^{\circ} \mathrm{C}\right)$ of MCPM to be 1.19 as compared to an experimental value of $1.14 .^{63}$ The computed free energy for dissolution of MPCA is exothermic $(-10.5 \mathrm{~kJ} / \mathrm{mol})$ unlike MCPM, which is consistent with the lack of stability of the phase at ambient conditions (see Table 8 for a comparison of free energies of dissolution for bulk phases vs experiment). In Table 9 we compare the experimental and force field optimized cell parameters for MCPA and MCPM. Note that in the case of MCPA it was necessary to lower the space group symmetry to $\mathrm{P} 1$ so that the hydrogen atoms were bonded to just a single phosphate anion, rather than bridging between two groups, as is the case for two hydrogen positions in the neutron refined structure. Despite this, the final optimized structure is in good agreement with experiment for MCPA, whereas the monohydrate shows larger errors. However, as already noted, MCPM is a triclinic structure and so non-trivial to reproduce. Given that the interactions between both calcium and dihydrogen phosphate with water are derived to reproduce the properties of the ions in aqueous solution, it is perhaps not surprising that hydrate structures are more challenging to describe with a single common model. The use of more sophisticated water models, which include either polarization and/or charge redistribution, in future work may go some way towards improving this situation.

Although the mechanical properties and hardness of calcium phosphate are of general interest because of their relevance to biomaterials, information on the bulk and other moduli of MCPA/MCPM is hard to find in the literature. In Table 9 we give the calculated bulk and shear moduli, which show that the monohydrate appears to be stiffer than the anhydrous material and that both have elastic moduli of a similar order of magnitude to bone.

\section{2) Ion Pairing}


As a further and last test of our force field, we have calculated the ion pairing free energy between each of the phosphate species and calcium. Indeed, this is a particularly significant property to test here since the primary objective of this force field will be to study crystallization processes, including pre-nucleation cluster formation, aggregation and eventually evolution into amorphous nanoparticles.

Given that the timescale for water exchange within the calcium coordination shell using the present model is $200 \mathrm{ps}$, the free energy of ion pairing has been mapped using two collective variables, namely the calcium water coordination number and calcium-phosphorus distance, in order to ensure convergence during the simulations, which were each run for up to $300 \mathrm{~ns}$. The 2D free energy landscapes are shown in Figure 3, together with the 1D profile projected along the Ca-P distance. As expected on the basis of previous studies on calcium carbonate ion pairing, ${ }^{17}$ for both $\left[\mathrm{CaPO}_{4}\right]^{-}$and $\left[\mathrm{CaHPO}_{4}\right]^{0}$ ion pairs four distinct minima can be identified in the plots. The two deepest ones, at short distance, correspond to a bi-dentate and a mono-dentate contact ion pair configuration. One corresponds to a solvent-shared configuration, where the cation and the anion are separated by one water molecule, i.e. they share part of their solvation sphere. The last minimum, shallower and at a larger distance $(\sim 7 \AA)$, corresponds to a state where the ions are separated by two layers of water molecules, i.e. the contact is through the ion solvation spheres.

$\left[\mathrm{CaH}_{2} \mathrm{PO}_{4}\right]^{+}$has a free energy profile that exhibits some differences and some similarities to the other ion pairs. The solvent-shared and the solvent separated states are easily recognizable and fall at about the same distance as the other species. The contact ion pair is also present, but only in a mono-dentate configuration that seems to be much less stable than the solvent-shared one. This would partly explain the much higher solubility and lower stability of MCP phases with 
respect to the DCP, TCP and apatite phases. Similarly, $\mathrm{HPO}_{4}{ }^{2-}$ and $\mathrm{PO}_{4}^{3-}$ species (e.g. Posner's cluster) and amorphous species have largely been reported during the crystallization of calcium phosphate despite $\mathrm{H}_{2} \mathrm{PO}_{4}{ }^{-}$being a dominant species in solution at biogenic $\mathrm{pH}$. However, in the work of Habraken et al. $\mathrm{H}_{2} \mathrm{PO}_{4}^{-}$is proposed to act as one of the ligands to $\mathrm{Ca}^{2+}$ during the formation of pre-nucleation species along with $\mathrm{HPO}_{4}{ }^{2-}$, . While this appears to be at odds with the results obtained for the ion pairing calculations, a full simulation of the free energy of multiple binding is required to properly examine whether $\mathrm{H}_{2} \mathrm{PO}_{4}{ }^{-}$can form a stable contact species.

Experimental values for the association constants $\left(K_{a}\right)$ of the three ion pairs are available from Busenberg and Plummer from which ion pairing free energies can then be calculated as;

$$
\Delta G=-k_{B} T \ln \left[1 / K_{a}\right]
$$

where $T$ is the temperature and $k_{B}$ is Boltzmann's constant. The corresponding values, calculated at $300 \mathrm{~K}$, are reported in Table 10 as $\Delta G_{\text {exp. }}$ The calculated data $\left(\Delta G_{F F}\right)$ have been extracted from our pairing free energy data using the Fuoss equation. ${ }^{64}$ In the latter case, ions are assumed to be uniformly charged spherical particles, which is not the case for phosphate species and therefore this should be considered only as an approximation. However, this approach provides one possible definition for the boundary between the bound and unbound state, along with the associated correction to the standard state.

The experimental and calculated standard free energies of ion pairing, $\Delta G_{\text {exp }}$ and $\Delta G_{F F}$, are in good agreement for all three anions, with the stability of $\left[\mathrm{CaHPO}_{4}\right]^{0}$ being slightly overestimated, while those of $\left[\mathrm{CaH}_{2} \mathrm{PO}_{4}\right]^{+}$and $\left[\mathrm{CaPO}_{4}\right]^{-}$are slightly underestimated. All values are essentially within ambient thermal energy, $k_{B} T$, of the experimental values and so any discrepancy is close to the limit of uncertainty due to intrinsic fluctuations. One of the ambiguities in comparing computed binding energies to experiment lies in the definition of the bound state. Depending on 
whether the measurement uses a spectroscopic technique or, as in this case, the inferred presence of ion pairs from the free ion concentrations, different results could potentially be obtained. For example, a spectroscopic measurement may be able to distinguish a contact ion pair from a solvent-shared or solvent separated state if the timescale for the measurement is faster than the interchange between configurations. Here we have chosen the Bjerrum radius as the limit of the bound state, which encompasses all of the evident minima associated with ion pairing, except for the solvent separated state of the $\left[\mathrm{CaH}_{2} \mathrm{PO}_{4}\right]^{+}$ion pair, which may make a small contribution to the underestimation of binding for this case. This aside, the current results are consistent with the experimental association constants encapsulating the contact, solvent-shared and solvent separated ion pairs for calcium phosphate, though it is not possible to rule out a small contribution from further ion association events.

\section{CONCLUSIONS}

A new force field has been derived for aqueous calcium phosphate systems covering all three possible anionic species. While the primary focus has been on ensuring that the experimental thermodynamics are accurately reproduced where known, both structural and mechanical properties for the solid phases have also been included in the fit. Despite the thermodynamic emphasis, it appears that the accuracy of the results for other properties is comparable to existing non-polarizable force fields. For some cases where there is an absence of direct experimental data, ab initio calculations were used to provide reference data. This is especially the case for species in aqueous solution where we have computed free energies of hydration using molecular 
quantum mechanical calculations and determined the radial distribution functions for water around the anions using ab initio molecular dynamics.

The ultimate test for the present force field is in the calculation of the free energy for ion pairing and the corresponding association constants. For all three phosphate anions considered here, the ion pairing with calcium is in excellent agreement with previous experiments. The error in the free energies being less than ambient thermal energy, $k_{B} T$ and therefore within the uncertainty of the method. As a result, we have demonstrated that the present model forms a reliable basis for the study of the thermodynamics of ion association in calcium phosphate solutions. This provides a sound basis for the study of the stability of pre-nucleation clusters in these systems, such as the $\mathrm{Ca}\left(\mathrm{HPO}_{4}\right)_{3}{ }^{4-}$ species proposed by Habraken et al. The study of such species will be examined in a subsequent manuscript. 

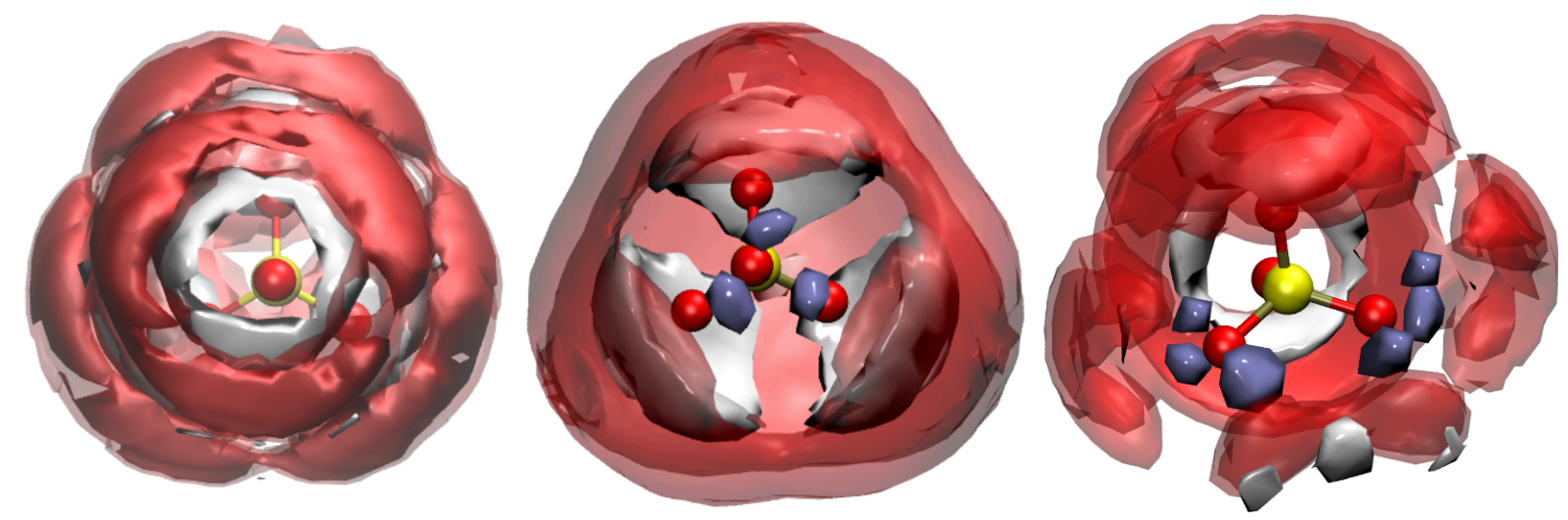

Figure 1. Representation of the water structure around the phosphate species; from left to right: $\mathrm{PO}_{4}{ }^{3-}, \mathrm{HPO}_{4}{ }^{2-}$, and $\mathrm{H}_{2} \mathrm{PO}_{4}^{-}$. Isosurfaces for $\mathrm{O}$ and $\mathrm{H}$ atoms of water are represented in red and white respectively; isosurfaces for $\mathrm{H}$ atoms of phosphate are represented in purple. Oxygen and phosphorus atoms are colored in red and yellow, respectively. 

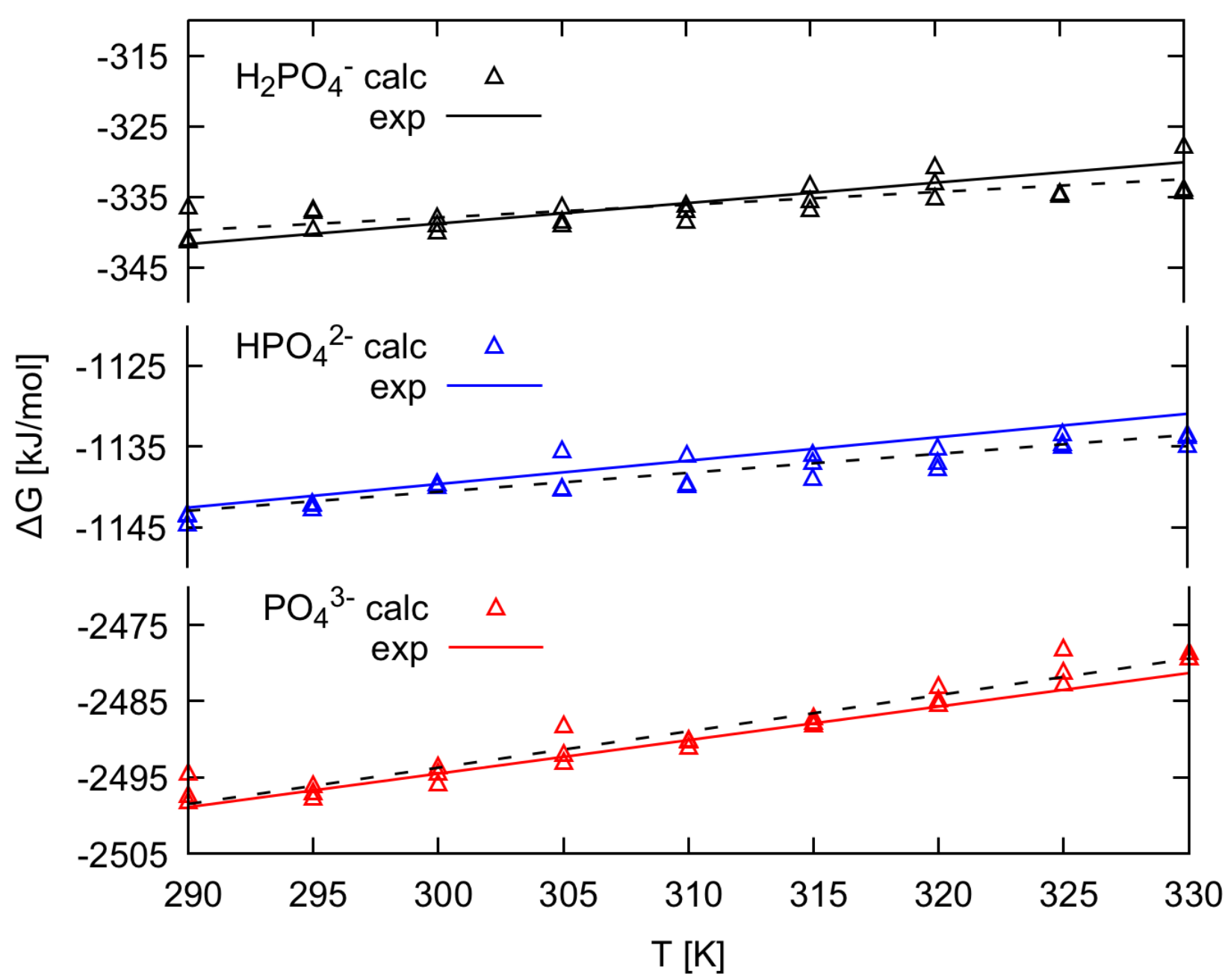

Figure 2. Free energies of solvation $(\Delta \mathrm{G})$ of phosphate species as a function of temperature $(\mathrm{T})$. The result of a least-squares linear fit is shown as a dashed line, while the solid line represents the slope that would be expected from the data of Marcus ${ }^{40}$ shifted to coincide with our calculated free energy at $300 \mathrm{~K}$ : values for enthalpies $(\Delta \mathrm{H})$ and entropies $(\Delta \mathrm{S})$ are reported in Table 3. 

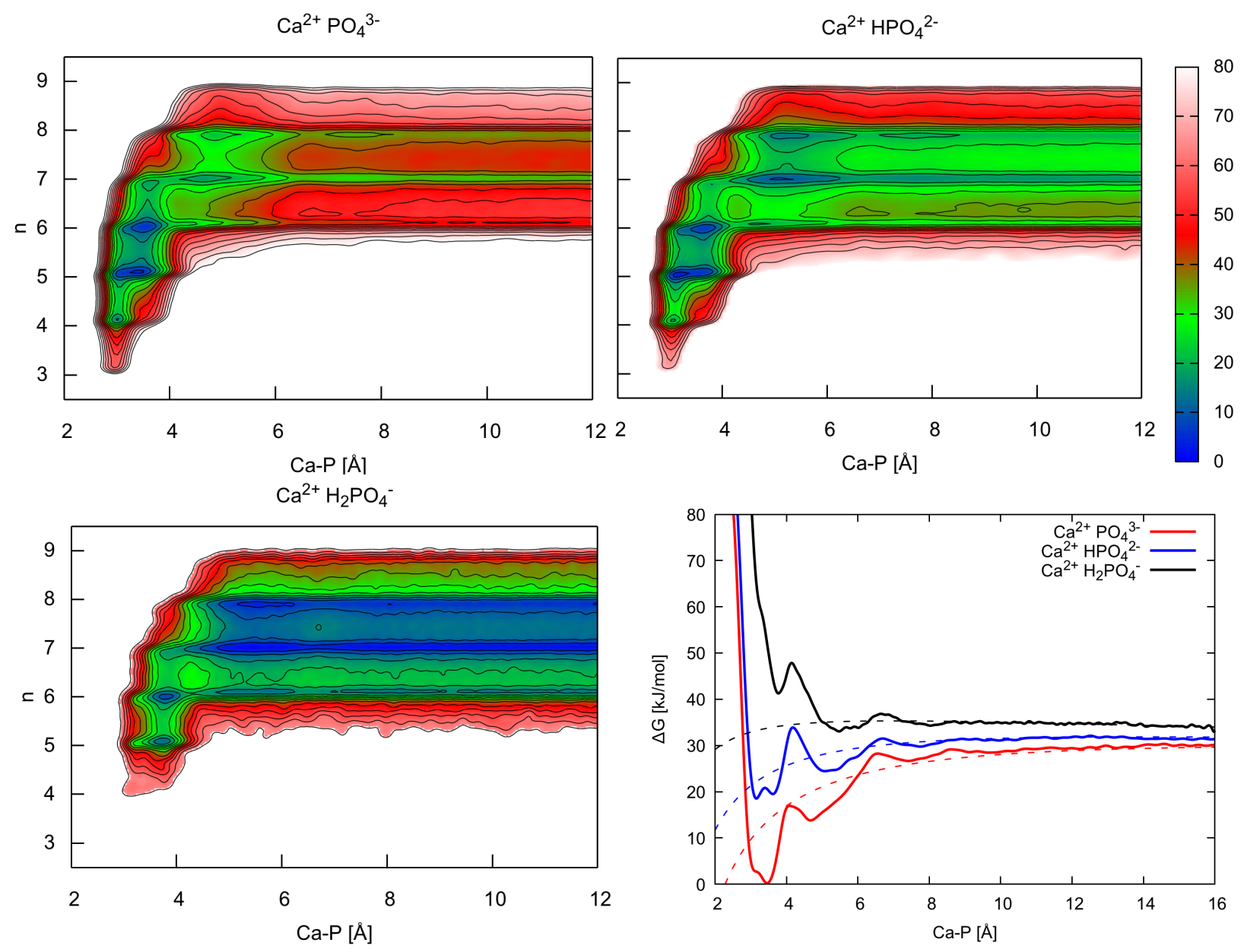

Figure 3 Ion pairing free energy profiles for the calcium phosphate species as a function of the Ca-P distance and the coordination number of calcium ions with the oxygen of water (n). The projection of the free energy along the Ca-P distance is reported in the bottom panel, together with the ideal curve for two charged point particles in a dielectric continuum that has a dielectric constant that corresponds to SPC/Fw water at 298.15 K (dashed lines). 
TABLES.

Table 1 Intramolecular force field parameters for the phosphate $\left(\mathrm{PO}_{4}{ }^{3-}\right)$, hydrogen phosphate $\left(\mathrm{HPO}_{4}{ }^{2-}\right)$ and dihydrogen phosphate $\left(\mathrm{H}_{2} \mathrm{PO}_{4}^{-}\right)$anions as derived in the present work. Here the atoms are labelled as $\mathrm{P} 1$ and $\mathrm{O} 7$ for $\mathrm{PO}_{4}^{3--} ; \mathrm{P} 1, \mathrm{O} 8, \mathrm{H} 8$, and $\mathrm{O} 9$ for $\mathrm{HPO}_{4}{ }^{2-} ; \mathrm{P} 2, \mathrm{O} 10, \mathrm{H} 10, \mathrm{O} 11$ for $\mathrm{H}_{2} \mathrm{PO}_{4}^{-}$, where $\mathrm{O} 8$ and $\mathrm{O} 10$ are the oxygen atoms bound to hydrogen. The functional form of the terms is defined in the main text. For the bond-bond cross terms the two equilibrium bond distances are given in the order corresponding to the two terminal atoms as specified. Where both values are identical then only a single value is listed.

\begin{tabular}{|c|c|c|c|c|c|}
\hline & $\begin{array}{l}k_{3}^{\text {angle }} \\
\left(\mathrm{eVrad}^{-2}\right)\end{array}$ & $\begin{array}{l}k_{3}^{\text {bond-bond }} \\
\left(\mathrm{eV} \AA^{-2}\right)\end{array}$ & $\begin{array}{l}k_{3}^{\text {bond-angle }} \\
\left(\mathrm{eV} \AA^{-1} \mathrm{rad}^{-1}\right)\end{array}$ & $\begin{array}{l}r_{0} \\
(\AA)\end{array}$ & $\begin{array}{l}\theta_{0} \\
\left({ }^{\circ}\right)\end{array}$ \\
\hline \multirow[t]{2}{*}{ O7-P1-O7 } & 8.9168 & 2.5983 & 3.0 & 1.5946 & 109.5 \\
\hline & $\begin{array}{l}k_{3}^{\text {angle }} \\
\left(\mathrm{eVrad}^{-2}\right)\end{array}$ & $\begin{array}{l}k_{3}^{\text {bond-bond }} \\
\left(\mathrm{eV} \AA^{-2}\right)\end{array}$ & $r_{0}(\AA)$ & $\begin{array}{l}\theta_{0} \\
\left(^{\circ}\right)\end{array}$ & \\
\hline O8-P1-O9 / O10-P2-O11 & 4.4066 & 2.9101 & $1.60 / 1.52$ & 109.5 & \\
\hline O9-P1-O9 / O11-P2-O11 & 11.875 & 1.6199 & 1.52 & 109.5 & \\
\hline \multirow[t]{2}{*}{ O10-P2-O10 } & 11.875 & 1.6199 & 1.60 & 109.5 & \\
\hline & $\begin{array}{l}k_{2} \\
\left(\mathrm{eV} \AA^{-2}\right)\end{array}$ & $r_{0}(\AA)$ & & & \\
\hline P1-O7 & 31.662 & 1.5946 & & & \\
\hline $\mathrm{P} 1-\mathrm{O} 8$ / P2-O10 & 24.2341 & 1.60 & & & \\
\hline P1-O9 / P2-O11 & 43.1412 & 1.52 & & & \\
\hline \multirow[t]{2}{*}{$\mathrm{O} 8-\mathrm{H} 8 / \mathrm{O} 10-\mathrm{H} 10$} & 43.1526 & 0.98 & & & \\
\hline & $\begin{array}{l}k_{3}^{\text {angle }} \\
\left(\mathrm{eVrad}^{-2}\right)\end{array}$ & $\begin{array}{l}\theta_{0} \\
\left(^{\circ}\right)\end{array}$ & & & \\
\hline \multirow[t]{2}{*}{ H8-O8-P1 / H10-O10-P2 } & 2.9055 & 111.4 & & & \\
\hline & $\begin{array}{l}k_{4}^{\text {torsion }} \\
(\mathrm{eV})\end{array}$ & & & & \\
\hline $\begin{array}{l}\text { H8-O8-P1-O9 / H10-O10-P2-O10 / } \\
\text { H10-O10-P2-O11 }\end{array}$ & 0.042272 & & & & \\
\hline
\end{tabular}


Table 2 Intermolecular potential parameters used in the present work between all pairs of calcium cations, phosphate anions and water molecules. Phosphate atoms are labelled as in Table 1. Hydrogen and oxygen of water are labelled as $\mathrm{H} 2$ and $\mathrm{O} 2$, respectively. All intermolecular potentials are truncated at $9 \AA$ using an MDF taper over the last $3 \AA$ to enforce a smooth transition of the energy and forces to zero. The precise forms are defined in the main text. For the Buckingham potentials $\mathrm{C}_{\text {buck }}$ was equal to 0 for all pair coefficients.

\begin{tabular}{|c|c|c|}
\hline Buckingham & $\begin{array}{c}A_{b u c k} \\
(\mathrm{eV})\end{array}$ & $\begin{array}{c}\rho_{\text {buck }} \\
(\AA)\end{array}$ \\
\hline Ca-P1 / Ca-P2 & 2132.9786 & 0.3428 \\
\hline $\mathrm{Ca}-\mathrm{O} 7$ & 2510.878 & 0.276289 \\
\hline $\mathrm{Ca}-\mathrm{O} 8$ & 2010.878 & 0.276289 \\
\hline $\mathrm{Ca}-\mathrm{O9}$ & 2590.878 & 0.276289 \\
\hline $\mathrm{Ca}-\mathrm{O} 10$ & 1860.062 & 0.276289 \\
\hline $\mathrm{Ca}-\mathrm{O} 11$ & 2396.562 & 0.276289 \\
\hline $\mathrm{O} 2-\mathrm{O} 7$ & 12534.455 & 0.2451 \\
\hline $\mathrm{O} 2-\mathrm{O} 8$ & 19534.455 & 0.2151 \\
\hline $\mathrm{O} 2-\mathrm{O} 9$ & 19534.455 & 0.2426 \\
\hline $\mathrm{O} 2-\mathrm{O} 10$ & 7500.000 & 0.2200 \\
\hline $\mathrm{O} 2-\mathrm{O} 11$ & 15000.000 & 0.2350 \\
\hline $\begin{array}{l}\mathrm{O} 7-\mathrm{O} 7 \text { / O7-O8 / O7-O9 / } \\
\mathrm{O} 7-\mathrm{O} 10 \text { / O7-O11 / O8-O8 } \\
\text { / O8-O9 / O8-O10 / O8- } \\
\text { O11 / O9-O9 / O9-O10 / } \\
\text { O9-O11 / O10-O10 / O10- } \\
\text { O11 / O11-O11 }\end{array}$ & 12534.455 & 0.202 \\
\hline Lennard-Jones & $\begin{array}{l}\varepsilon_{L J} \\
(\mathrm{eV})\end{array}$ & $\begin{array}{l}r_{L J} \\
(\AA)\end{array}$ \\
\hline $\mathrm{O} 2-\mathrm{O} 10$ & 0.01 & 2.75 \\
\hline $\mathrm{O} 2-\mathrm{O} 2$ & 0.00674 & 3.165492 \\
\hline $\mathrm{Ca}-\mathrm{O} 2$ & 0.00095 & 3.35 \\
\hline Lennard-Jones & \multicolumn{2}{|c|}{$\begin{array}{c}A_{L J} \\
\left(\mathrm{eV} \AA^{12}\right)\end{array}$} \\
\hline $\mathrm{H} 2-\mathrm{O} 8$ / H2-O11 & \multicolumn{2}{|c|}{28.0} \\
\hline $\mathrm{H} 2-\mathrm{O} 10$ & \multicolumn{2}{|c|}{15.0} \\
\hline $\begin{array}{l}\mathrm{H} 8-\mathrm{O} 7 \text { / H8-O8 / H8-O9 / } \\
\mathrm{H} 8-\mathrm{O} 10 / \mathrm{H} 8-\mathrm{O} 11\end{array}$ & \multicolumn{2}{|c|}{54.0} \\
\hline $\begin{array}{l}\text { H10-O7 / H10-O8 / H10- } \\
\text { O9 / H10-O10 / H10-O11 }\end{array}$ & \multicolumn{2}{|c|}{54.0} \\
\hline $\mathrm{P} 2-\mathrm{O} 10$ / P2-O11 & \multicolumn{2}{|c|}{1000.0} \\
\hline
\end{tabular}


Table 3 Hydration free energy $\left(\Delta \mathrm{G}, \mathrm{kJ} \mathrm{mol}^{-1}\right)$, enthalpy $\left(\Delta \mathrm{H}, \mathrm{kJ} \mathrm{mol}^{-1}\right)$ and entropy $\left(\Delta \mathrm{S}, \mathrm{J} \mathrm{mol}^{-1}\right.$ $\mathrm{K}^{-1}$ ) at $300 \mathrm{~K}$ for the phosphate species as obtained with our force field (FF); estimates based on quantum mechanical calculations (QM, present work), and results from previous models and calculations are also reported. ${ }^{39-42}$ Intermolecular interactions were refined to reproduce $\Delta \mathrm{G}$, while $\Delta \mathrm{H}$ and $\Delta \mathrm{S}$ were not explicitly fitted and are provided for validation.

\begin{tabular}{|c|c|c|c|c|c|c|c|c|c|c|}
\hline & \multicolumn{5}{|l|}{$\Delta \mathrm{G}$} & \multicolumn{3}{|l|}{$\Delta \mathrm{H}$} & \multicolumn{2}{|l|}{$\Delta S$} \\
\hline & $\begin{array}{l}\text { Florian \& } \\
\text { Warshel }\end{array}$ & Moser & Marcus & QM & $\mathrm{FF}$ & George & Marcus & FF & Marcus & $\mathrm{FF}$ \\
\hline $\mathrm{PO}_{4}^{3-}$ & -2242.6 & $\begin{array}{l}-1936.4 \text { to } \\
-2452.7\end{array}$ & -2765 & -2494.4 & -2494.5 & -2665.2 & -2875 & -2636.7 & -440 & -477 \\
\hline $\mathrm{HPO}_{4}{ }^{2-}$ & -1025.0 & $\begin{array}{l}-871.5 \text { to } \\
-1113.8\end{array}$ & - & -1140.0 & -1139.7 & -1251.0 & - & -1211.1 & -291 & -235 \\
\hline $\mathrm{H}_{2} \mathrm{PO}_{4}^{-}$ & -284.5 & $\begin{array}{l}-241.8 \text { to } \\
-330.0\end{array}$ & -465 & -337.4 & -338.8 & -318.0 & -520 & -392.2 & -290 & -181 \\
\hline
\end{tabular}


Table 4 Calculated structural and mechanical properties for $\alpha$-tricalcium phosphate. The experimental structure is taken from the work of Mathew et al ${ }^{55}$ Results are also given based on calculations using the force fields of Hauptmann et al. ${ }^{52}$ and Pedone et al. ${ }^{51}$ In addition, the results of DFT calculations from Liang et $a l .{ }^{56}$ using the PBE functional are included for comparison. Relative differences with respect to the experimental data are reported into parenthesis.

\begin{tabular}{|l|l|l|l|l|l|}
\hline Property & Exp & $\begin{array}{l}\text { Rigid FF } \\
\text { This work }\end{array}$ & $\begin{array}{l}\text { Rigid FF } \\
\text { Hauptmann }\end{array}$ & $\begin{array}{l}\text { Shell FF } \\
\text { Pedone }\end{array}$ & $\begin{array}{l}\text { DFT-PBE } \\
\text { Liang }\end{array}$ \\
\hline$a(\AA)$ & 12.887 & $12.890(0 \%)$ & $13.001(+0.9 \%)$ & $12.727(-1.2 \%)$ & $12.861(-0.2 \%)$ \\
\hline$b(\AA)$ & 27.280 & $27.730(+1.6 \%)$ & $27.495(+0.8 \%)$ & $27.529(+0.9 \%)$ & $27.225(-0.2 \%)$ \\
\hline$c(\AA)$ & 15.219 & $15.372(+1.0 \%)$ & $15.268(+0.3 \%)$ & $15.304(+0.6 \%)$ & $15.189(-0.2 \%)$ \\
\hline$\beta\left({ }^{\circ}\right)$ & 126.20 & $126.81(+0.5 \%)$ & $125.31(-0.7 \%)$ & $126.86(+0.5 \%)$ & $126.20(0 \%)$ \\
\hline $\mathrm{K}(\mathrm{GPa})$ & & 70.8 & 125.6 & 82.3 & 75.9 \\
\hline $\mathrm{G}(\mathrm{GPa})$ & & 33.9 & 60.4 & 36.8 & 40.1 \\
\hline $\mathrm{C}_{11}(\mathrm{GPa})$ & & 97.8 & 211.9 & 121.7 & 127.4 \\
\hline $\mathrm{C}_{22}(\mathrm{GPa})$ & & 149.0 & 202.5 & 156.1 & 135.3 \\
\hline $\mathrm{C}_{33}(\mathrm{GPa})$ & & 113.5 & 208.8 & 120.7 & 123.0 \\
\hline $\mathrm{C}_{44}(\mathrm{GPa})$ & & 36.4 & 60.7 & 34.2 & 40.2 \\
\hline $\mathrm{C}_{55}(\mathrm{GPa})$ & & 42.0 & 53.0 & 40.9 & 42.7 \\
\hline $\mathrm{C}_{66}(\mathrm{GPa})$ & & 27.7 & 71.1 & 39.4 & 39.9 \\
\hline
\end{tabular}


Table 5 Calculated structural and mechanical properties for tuite ( $\gamma$-tricalcium phosphate). Experimental structural data are from Sugiyama et al. ${ }^{65}$ while the bulk modulus is from a highpressure equation of state. ${ }^{57}$ Results are also given based on calculations using the force fields of Hauptmann et al..$^{52}$ and Pedone et al.. ${ }^{51}$ Relative differences with respect to the experimental data are reported into parenthesis.

\begin{tabular}{|l|l|l|l|l|}
\hline Property & Exp & $\begin{array}{l}\text { Rigid FF } \\
\text { This work }\end{array}$ & $\begin{array}{l}\text { Rigid FF } \\
\text { Hauptmann }\end{array}$ & $\begin{array}{l}\text { Shell FF } \\
\text { Pedone }\end{array}$ \\
\hline$a(\AA)$ & 5.2487 & $5.2484(0 \%)$ & $5.3809(+2.5 \%)$ & $5.1367(-2.1 \%)$ \\
\hline$c(\AA)$ & 18.6735 & $18.7485(+0.4 \%)$ & $18.6279(-0.2 \%)$ & $19.1642(+2.6 \%)$ \\
\hline $\mathrm{K}(\mathrm{GPa})$ & 100.8 & $118.3(+17.4 \%)$ & $237.2(+135.3 \%)$ & $122.9(+21.9 \%)$ \\
\hline $\mathrm{G}(\mathrm{GPa})$ & & 51.4 & 101.1 & 43.3 \\
\hline$\Delta \mathrm{U}(\gamma-\alpha)(\mathrm{kJ} / \mathrm{mol})$ & & -36.0 & +15.4 & -21.4 \\
\hline
\end{tabular}


Table 6 Calculated structural and mechanical properties for $\beta$-tricalcium phosphate. Here the experimental structure is taken from Yashima et al..$^{54}$ while the bulk modulus is estimated from indentation measurements on single crystals. ${ }^{66}$ Results are also given based on calculations using the force fields of Hauptmann et $a l^{52}$ and Pedone et al., ${ }^{51}$ as well as from the first principles calculations of Liang et $a .^{56}$ and Yin et al.. ${ }^{67}$ Relative differences with respect to the experimental data are reported into parenthesis.

\begin{tabular}{|l|l|l|l|l|l|l|}
\hline Property & Exp & $\begin{array}{l}\text { Rigid FF } \\
\text { This work }\end{array}$ & $\begin{array}{l}\text { Rigid FF } \\
\text { Hauptmann }\end{array}$ & $\begin{array}{l}\text { Shell FF } \\
\text { Pedone }\end{array}$ & $\begin{array}{l}\text { DFT-PBE } \\
\text { Liang }\end{array}$ & $\begin{array}{l}\text { DFT-LDA } \\
\text { Yin }\end{array}$ \\
\hline$a(\AA)$ & 10.4352 & $10.4757(+0.4 \%)$ & $10.6468(+2.0 \%)$ & $10.2842(-1.4 \%)$ & $10.3513(-0.8 \%)$ & $10.157(-2.7 \%)$ \\
\hline$c(\AA)$ & 37.4029 & $37.6414(+0.6 \%)$ & $37.1516(-0.7 \%)$ & $38.6134(+3.2 \%)$ & $36.8898(-1.4 \%)$ & $36.481(-2.5 \%)$ \\
\hline $\mathrm{K}(\mathrm{GPa})$ & 120.7 & $92.0(-23.8 \%)$ & $152.8(+26.6 \%)$ & $95.5(-20.9 \%)$ & $82.0(-32.1 \%)$ & \\
\hline $\mathrm{G}(\mathrm{GPa})$ & & 46.1 & 72.1 & 35.5 & 43.2 & \\
\hline $\begin{array}{l}\Delta \mathrm{U}(\beta-\alpha) \\
(\mathrm{kJ} / \mathrm{mol})\end{array}$ & +11.1 & +8.5 & -2.91 & -35.4 & -67.5 \\
\hline
\end{tabular}


Table 7 Calculated structural and mechanical properties for monetite $\left(\mathrm{CaHPO}_{4}\right)$. The experimental structure is taken from Catti et al.. ${ }^{59}$

\begin{tabular}{|l|l|l|l|}
\hline Property & Experiment & This work & $\begin{array}{l}\text { Error } \\
(\%)\end{array}$ \\
\hline$a(\AA)$ & 6.910 & 6.972 & +0.8 \\
\hline$b(\AA)$ & 6.627 & 6.656 & +0.5 \\
\hline$c(\AA)$ & 6.998 & 6.900 & -0.7 \\
\hline$\alpha\left(^{\circ}\right)$ & 96.34 & 92.80 & -3.5 \\
\hline$\beta\left(^{\circ}\right)$ & 103.82 & 104.16 & -0.3 \\
\hline$\gamma\left({ }^{\circ}\right)$ & 88.33 & 90.03 & -1.9 \\
\hline$K(\mathrm{GPa})$ & - & 67.6 & - \\
\hline$G(\mathrm{GPa})$ & - & 35.8 & - \\
\hline
\end{tabular}


1

2

3

4

5

6

7

8

9

Table 8 Free energies of dissolution $(\mathrm{kJ} / \mathrm{mol})$ for calcium phosphate phases as computed with the present force field at $298.15 \mathrm{~K}$ and 1 bar using the free energies of solvation from molecular dynamics and the free energy for the solid from lattice dynamics (but excluding zero point energy for consistence with molecular dynamics). Experimental values are provided as a guide, where estimates exist, though it should be noted that there are uncertainties in many cases. For $\beta$ $\mathrm{Ca}_{3}\left(\mathrm{PO}_{4}\right)_{2}$ an ordered structure was used in the calculations rather than having partial occupancy of the Ca sites.

\begin{tabular}{|l|l|l|l|}
\hline Phase & $\Delta \mathrm{G}_{\text {diss }}$ (experiment) & $\Delta \mathrm{G}_{\text {diss }}$ (calculated) & Error $(\%)$ \\
\hline$\alpha-\mathrm{Ca}_{3}\left(\mathrm{PO}_{4}\right)_{2}$ & $177.4^{69}$ & 174.8 & -1.5 \\
\hline$\beta-\mathrm{Ca}_{3}\left(\mathrm{PO}_{4}\right)_{2}$ & $137.6^{70}-186.6^{69}$ & 127.8 & $-7.1-31.5$ \\
\hline$\gamma-\mathrm{Ca}_{3}\left(\mathrm{PO}_{4}\right)_{2} ;$ tuite & - & 138.0 & - \\
\hline $\mathrm{CaHPO} \mathrm{PO}_{4} ;$ monetite & $37.5^{71}$ & 16.7 & -55.5 \\
\hline $\mathrm{CaHPO} \mathrm{HP}_{4} \cdot \mathrm{H}_{2} \mathrm{O} ;$ brushite & $37.5^{71}$ & -6.4 & -117.1 \\
\hline $\mathrm{Ca}\left(\mathrm{H}_{2} \mathrm{PO}_{4}\right)_{2} ; \mathrm{MCPA}$ & Highly soluble & - \\
\hline $\mathrm{Ca}\left(\mathrm{H}_{2} \mathrm{PO}_{4}\right)_{2} \cdot \mathrm{H}_{2} \mathrm{O} ; \mathrm{MCPM}$ & $6.5^{73}$, Highly soluble $^{72}$ & -10.5 & - \\
\hline
\end{tabular}


Table 9 Calculated structural and mechanical properties for monocalcium phosphate in anhydrous (MCPA) and monohydrate forms (MCPM). Experimental structures for MCPA and MCPM are taken from Dickens et al.$^{61}$ and Dickens and Bowen, ${ }^{60}$ respectively.

\begin{tabular}{|l|l|l|l|l|l|l|}
\hline Property & $\begin{array}{l}\text { MCPA } \\
\text { Experiment }\end{array}$ & $\begin{array}{l}\text { MCPA } \\
\text { This work }\end{array}$ & $\begin{array}{l}\text { Error } \\
(\%)\end{array}$ & $\begin{array}{l}\text { MCPM } \\
\text { Experiment }\end{array}$ & $\begin{array}{l}\text { MCPM } \\
\text { This work }\end{array}$ & $\begin{array}{l}\text { Error } \\
(\%)\end{array}$ \\
\hline$a(\AA)$ & 7.5577 & 7.4576 & -1.3 & 5.6261 & 5.3427 & -5.0 \\
\hline$b(\AA)$ & 8.2531 & 8.2950 & +0.5 & 11.8890 & 11.8926 & +0.0 \\
\hline$c(\AA)$ & 5.5504 & 5.6219 & +1.3 & 6.4731 & 6.9448 & -7.3 \\
\hline$\alpha\left(^{\circ}\right)$ & 109.87 & 110.12 & +0.2 & 98.63 & 97.81 & -0.8 \\
\hline$\beta\left(^{\circ}\right)$ & 93.68 & 94.22 & +0.6 & 118.26 & 118.13 & -0.1 \\
\hline$\gamma\left({ }^{\circ}\right)$ & 109.15 & 108.16 & -0.9 & 83.34 & 84.39 & +1.3 \\
\hline$K(\mathrm{GPa})$ & - & 11.7 & - & & 25.0 & \\
\hline$G(\mathrm{GPa})$ & - & 10.1 & - & & 12.1 & \\
\hline
\end{tabular}


Table 10 Ion pairing free energy $[\mathrm{kJ} / \mathrm{mol}]$ at $300 \mathrm{~K}$ between the phosphate species and $\mathrm{Ca}^{2+}$. Experimental values $\left(\Delta G_{\text {exp }}\right)$ are taken from Busenberg \& Plummer; ${ }^{68}$ calculated values $\left(\Delta G_{\mathrm{FF}}\right)$ have been extracted from our pairing free energy profile by applying the Fuoss equation. ${ }^{64}$

\begin{tabular}{|l|l|l|l|l|}
\hline & $\Delta G_{e x p}$ & $\Delta G_{F F}$ & Error & Error $(\%)$ \\
\hline $\mathrm{Ca}^{2+} \mathrm{PO}_{4}{ }^{3-}$ & -37.1 & -35.9 & +1.2 & +3.2 \\
\hline $\mathrm{Ca}^{2+} \mathrm{HPO}_{4}{ }^{2-}$ & -15.7 & -17.9 & -2.2 & -14.0 \\
\hline $\mathrm{Ca}^{2+} \mathrm{H}_{2} \mathrm{PO}_{4}^{-}$ & -8.1 & -5.0 & +3.1 & +38.3 \\
\hline
\end{tabular}




\section{ASSOCIATED CONTENT}

The Supporting Information is available free of charge on the ACS Publications website at DOI: Radial pair distribution functions.

\section{AUTHOR INFORMATION \\ Corresponding Author \\ *raffaella.demichelis@curtin.edu.au}

\section{Author Contributions}

The manuscript was written through contributions of all authors. All authors have given approval to the final version of the manuscript

\section{Funding Sources}

ARC Discovery grant: DP160100677

ARC Future Fellowship: FT130100463

Engineering and Physical Sciences Research Council grant: EP/I001514/1

\section{ACKNOWLEDGMENT}

RD, PR and JDG thank the Australian Research Council for funding through FT130100463 and DP160100677. RD thanks Curtin University for funding through the Curtin Research Fellowship scheme. The Australian National Computational Infrastructure (NCI) and the Pawsey Supercomputing Centre are acknowledged for the provision of computing resources. JHH, CLF and RIM thank the Engineering and Physical Sciences Research Council [grant number 
EP/I001514/1]. This Programme Grant funds the Materials Interface with Biology (MIB) consortium. Some computational time on ARCHER was also provided through this grant. Further access to the facilities of ARCHER was provided through their membership of the UK's HPC Materials Chemistry Consortium, which is funded by EPSRC (grant number EP/L000202). ARCHER is the UK's national high-performance computing service, which is funded by the Office of Science and Technology through EPSRC's High End Computing Programme.

\section{REFERENCES}

(1) Gebauer, D.; Voelkel, A.; Coelfen, H. Stable Prenucleation Calcium Carbonate Clusters. Science 2008, 322, 1819-1822.

(2) Demichelis, R.; Raiteri, P.; Gale, J. D.; Quigley, D.; Gebauer, D. Stable Prenucleation Mineral Clusters Are Liquid-Like Ionic Polymers. Nat. Commun. 2011, 2, 590.

(3) Wallace, A. F.; Hedges, L. O.; Fernandez-Martinez, A.; Raiteri, P.; Gale, J. D.; Waychunas, G. A.; Whitelam, S.; Banfield, J. F.; De Yoreo, J. J. Microscopic Evidence for Liquid-Liquid Separation in Supersaturated CaCO3 Solutions. Science 2013, 341, 885-889.

(4) Posner, A. S.; Betts, F. Synthetic Amorphous Calcium Phosphate and Its Relation to Bone Mineral Structure. Acc. Chem. Res 1975, 8, 273-281.

(5) Wang, L.; Li, S.; Ruiz-Agudo, E.; Putnis, C. V.; Putnis, A. Posner's Cluster Revisited: Direct Imaging of Nucleation and Growth of Nanoscale Calcium Phosphate Clusters at the Calcite-Water Interface. CrystEngComm 2012, 14, 6252-6255.

(6) Habraken, W. J. E. M.; Tao, J.; Brylka, L. J.; Friedrich, H.; Bertinetti, L.; Schenk, A. S.; Verch, A.; Dmitrovic, V.; Bomans, P. H. H.; Frederik, P. M.; et al. Ion-Association Complexes Unite Classical and Non-Classical Theories for the Biomimetic Nucleation of Calcium Phosphate. Nat. Commun. 2013, 4, 1507.

(7) Zhang, Q.; Jiang, Y.; Gou, B.-D.; Huang, J.; Gao, Y.-X.; Zhao, J.-T.; Zheng, L.; Zhao, Y.-D.; Zhang, T.-L.; Wang, K. In Situ Detection of Calcium Phosphate Clusters in Solution and Wet Amorphous Phase by Synchrotron X-Ray Absorption Near-Edge Spectroscopy at Calcium K-Edge. Cryst. Growth Des. 2015, 15, 2204-2210.

(8) Treboux, G.; Layrolle, P.; Kanzaki, N.; Onuma, K.; Ito, A. Symmetry of Posner's Cluster. J. Am. Chem. Soc. 2000, 122, 8323-8324.

(9) Treboux, G.; Layrolle, P.; Kanzaki, N.; Onuma, K.; Ito, A. Existence of Posner's Cluster in Vacuum. J. Phys. Chem. A 2000, 104, 5111-5114.

(10) Mancardi, G.; Tamargo, C. E. H.; di Tommaso, D.; de Leeuw, N. H. Detection of Posner's Clusters During Calcium Phosphate Nucleation: a Molecular Dynamics Study. Journal of Materials Chemistry B 2017, 20,1-11.

(11) Zahn, D. Mechanisms of Calcium and Phosphate Ion Association in Aqueous Solution. Z. anorg. allg. Chem. 2004, 630, 1507-1511.

(12) Charifson, P. S.; Hiskey, R. G.; Pedersen, L. G.; Kuyper, L. F. Free-Energy Calculations 
on Calcium and Magnesium Complexes - Protein and Phospholipid Model Systems. $J$. Comput. Chem. 1991, 12, 899-908.

(13) Kawska, A.; Hochrein, O.; Brickmann, J.; Kniep, R.; Zahn, D. The Nucleation Mechanism of Fluorapatite-Collagen Composites: Ion Association and Motif Control by Collagen Proteins. Angew. Chem. Int. Ed. 2008, 47, 4982-4985.

(14) Ma, J. A Molecular Dynamics Study on the Nucleation of Calcium Phosphate Regulated by Collagen. J. Mater. Sci. 2014, 49, 3099-3106.

(15) Brooks, B. R.; Bruccoleri, R. E.; Olafson, B. D.; States, D. J.; Swaminathan, S.; Karplus, M. CHARMM: a Program for Macromolecular Energy, Minimization, and Dynamics Calculations. Journal of ... 1983.

(16) Raiteri, P.; Gale, J. D.; Quigley, D.; Rodger, P. M. Derivation of an Accurate ForceField for Simulating the Growth of Calcium Carbonate From Aqueous Solution: a New Model for the Calcite- Water Interface. J. Phys. Chem. C 2010, 114, 5997-6010.

(20) Plimpton, S. Fast Parallel Algorithms for Short-Range Molecular Dynamics. J. Comput. Phys. 1995, 117, 1-19.

(21) Zwanzig, R. High-Temperature Equation of State by a Perturbation Method. I. Nonpolar Gases. J. Chem. Phys. 1954, 22, 1420.

(22) Raiteri, P.; Laio, A.; Gervasio, F. L.; Micheletti, C.; Parrinello, M. Efficient Reconstruction of Complex Free Energy Landscapes by Multiple Walkers Metadynamics. J. Phys. Chem. B 2006, 110, 3533-3539.

(23) Barducci, A.; Bussi, G.; Parrinello, M. Well-Tempered Metadynamics: a Smoothly Converging and Tunable Free-Energy Method. Phys. Rev. Lett. 2008, 100, 20603.

(24) Hummer, G.; Pratt, L. R.; Garcia, A. Ion Sizes and Finite-Size Corrections for IonicSolvation Free Energies. J. Chem. Phys. 1997, 107, 9275-9277.

(25) Tribello, G. A.; Bonomi, M.; Branduardi, D.; Camilloni, C.; Bussi, G. Computer Physics Communications. Comput. Phys. Commun. 2014, 185, 604-613.

(26) Hutter, J.; Iannuzzi, M.; Schiffmann, F.; VandeVondele, J. CP2K:Atomistic Simulations of Condensed Matter Systems. WIREs Comput Mol Sci 2014, 4, 15-25.

(27) VandeVondele, J.; Krack, M.; Mohamed, F.; Parrinello, M.; Chassaing, T.; Hutter, J. Quickstep: Fast and Accurate Density Functional Calculations Using a Mixed Gaussian and Plane Waves Approach. Comput. Phys. Commun. 2005, 167, 103-128.

(28) Goedecker, S.; Teter, M.; Hutter, J. Separable Dual-Space Gaussian Pseudopotentials. Phys. Rev. B 1996, 54, 1703-1710.

(29) VandeVondele, J.; Hutter, J. An Efficient Orbital Transformation Method for Electronic Structure Calculations. J. Chem. Phys. 2003, 118, 4365-4369.

(30) Wang, J.; Román-Pérez, G.; Soler, J. M.; Artacho, E.; Fernández-Serra, M. V. Density, Structure, and Dynamics of Water: the Effect of Van Der Waals Interactions. J. Chem. Phys. 2011, 134, 024516.

(31) DiStasio, R. A., Jr.; DiStasio, R. A.; Santra, B.; Li, Z.; Wu, X.; Car, R. The Individual and Collective Effects of Exact Exchange and Dispersion Interactions on the $\mathrm{Ab}$ 
Initiostructure of Liquid Water. J. Chem. Phys. 2014, 141, 084502.

Guidon, M.; Hutter, J.; VandeVondele, J. Auxiliary Density Matrix Methods for Hartree-Fock Exchange Calculations. J. Chem. Theory Comput. 2010, 6, 2348-2364. Wu, Y.; Chen, H.; Wang, F.; Paesani, F.; Voth, G. A. An Improved Multistate Empirical Valence Bond Model for Aqueous Proton Solvation and Transport. J. Phys. Chem. B 2008, 112, 467-482.

Handbook of Chemistry and Physics, 82nd ed.; Lide, D. R., Ed.; CRC press, 2001. Shao, Y.; Gan, Z.; Epifanovsky, E.; Gilbert, A. T. B.; Wormit, M.; Kussmann, J.; Lange, A. W.; Behn, A.; Deng, J.; Feng, X.; et al. Advances in Molecular Quantum Chemistry Contained in the Q-Chem 4 Program Package. Mol. Phys. 2014, 113, 184-215. Marenich, A. V.; Olson, R. M.; Kelly, C. P.; Cramer, C. J.; Truhlar, D. G. SelfConsistent Reaction Field Model for Aqueous and Nonaqueous Solutions Based on Accurate Polarized Partial Charges. J. Chem. Theory Comput. 2007, 3, 2011-2033. Zhao, Y.; Truhlar, D. G. The M06 Suite of Density Functionals for Main Group Thermochemistry, Thermochemical Kinetics, Noncovalent Interactions, Excited States, and Transition Elements: Two New Functionals and Systematic Testing of Four M06Class Functionals and 12 Other Functionals. Theor. Chem. Acc. 2007, 120, 215-241. Pegado, L.; Marsalek, O.; Jungwirth, P.; Wernersson, E. Solvation and Ion-Pairing Properties of the Aqueous Sulfate Anion: Explicit Versus Effective Electronic Polarization. Phys. Chem. Chem. Phys. 2012, 14, 10248.

George, P.; Witonsky, R. J.; Trachtman, M.; Wu, C.; Dorwart, W .; Richman, L.; Richman, W.; Shurayh, F.; Lentz, B. "Squiggle-H2O." an Enquiry Into the Importance of Solvation Effects in Phosphate Ester and Anhydride Reactions. Biochim. Biophys. Acta 1970, 223, 1-15.

Marcus, Y. A Simple Empirical Model Describing the Thermodynamics of Hydration of Ions of Widely Varying Charges, Sizes, and Shapes. Biophys. Chem. 1994, 51, 111-127. Florián, J.; Warshel, A. Calculations of Hydration Entropies of Hydrophobic, Polar, and Ionic Solutes in the Framework of the Langevin Dipoles Solvation Model. J. Phys. Chem. B 1999, 103, 10282-10288.

Moser, A. T. Computational Investigation of Nucleic Acids, 2009, pp 1-158.

Florián, J.; Warshel, A. Langevin Dipoles Model for Ab Initio Calculations of Chemical Processes in Solution: Parametrization and Application to Hydration Free Energies of Neutral and Ionic Solutes and Conformational Analysis in Aqueous Solution. J. Phys. Chem. B 1997, 101, 5583-5595.

Taylor, M. G.; Simkiss, K.; Leslie, M. Computer Modelling of Phosphate Biominerals. Transfer of Parameters for Interatomic Potentials for Different Polymorphs of Divalent Metal Diphosphates. Faraday Trans. 1994, 90, 641-647.

Gale, J. D.; Henson, N. J. Derivation of Interatomic Potentials for Microporous Aluminophosphates From the Structure and Properties of Berlinite. Faraday Trans. 1994, 90, 3175-3175.

Meis, C.; Gale, J. D.; Boyer, L.; Carpena, J.; Gosset, D. Theoretical Study of Pu and Cs Incorporation in a Mono-Silicate Neodymium Fluoroapatite $\mathrm{Ca}_{9} \mathrm{Nd}\left(\mathrm{SiO}_{4}\right)\left(\mathrm{Po}_{4}\right)_{5} \mathrm{~F}_{2}$. $J$. Phys. Chem. A 2000, 104, 5380-5387.

Lee, W. T.; Dove, M. T.; Salje, E. Surface Relaxations in Hydroxyapatite. J. Phys.: Condens. Matter 2000, 12, 9829-9841. Mkhonto, D.; de Leeuw, N. H. A Computer Modelling Study of the Effect of Water on 
the Surface Structure and Morphology of Fluorapatite: Introducing a $\mathrm{Ca}_{10}\left(\mathrm{Po}_{4}\right)_{6} \mathrm{~F}_{2}$ Potential Model. J. Mater. Chem. 2002, 12, 2633-2642.

(62) Martin, R. I.; Brown, P. W. Phase Equilibria Among Acid Calcium Phosphates. J. Am. Ceram. Soc. 1997, 80, 1263-1266.

(63) Fernandez, E.; Gil, F. J.; Ginebra, M. P.; Driessens, F.; Planell, J. A.; Best, S. M. Calcium Phosphate Bone Cements for Clinical Applications - Part I: Solution Chemistry. J Mater Sci Mater Med 1999, 10, 169-176.

(64) Fuoss, R. M.; Kraus, C. A. Properties of Electrolytic Solutions. III. the Dissociation Constant. J. Am. Chem. Soc. 1933, 55, 1019-1028.

(65) Sugiyama, K.; Tokonami, M. Structure and Crystal-Chemistry of a Dense Polymorph of 
Tricalcium Phosphate Ca3(Po4)2 - a Host to Accommodate Large Lithophile Elements in the Earths Mantle. Phys. Chem Miner. 1987, 15, 125-130.

(66) Viswanath, B.; Raghavan, R.; Gurao, N. P.; Ramamurty, U.; Ravishankar, N. Mechanical Properties of Tricalcium Phosphate Single Crystals Grown by Molten Salt Synthesis. Acta Biomaterialia 2008, 4, 1448-1454.

(67) Yin, X.; Stott, M. J.; Rubio, A. A- and B-Tricalcium Phosphate: a Density Functional Study. Phys. Rev. B 2003, 68, 3130-3138.

(68) Busenberg, E.; Plummer, N. L. Thermodynamics of Magnesian Calcite Solid-Solutions at $25 \mathrm{C}$ and 1 Atm Total Pressure. Geochim. Cosmochim. Ac. 1989, 53, 1189-1208.

(69) D.D. Wagman, W.H. Evans, V.B. Parker, R.H. Schumm, I. Halow, S.M. Bailey, K.L. Churney and R.L. Nuttall, J. Phys. Chem. Ref. Data, 1982, 11, Supplement No. 2 .

(70) M.B. Tomson, L. Vignona, Precipitation of phosphate minerals in waste water treatment systems, p 391, in Phosphate minerals, 1984, J.O. Nriagu and P.B. Moore (eds.), Springer-Verlag, New York

(71) W.F. Jaynes, P.A. Moore, Jr., D.M. Miller, J. Environ. Qual., 1999, 28, 530.

(72) L.C. Chow, in Octacalcium phosphate, L.C. Chow and E.D. Eanes (eds.), Monogr. Oral. Sci. Basel Karger, 2001, 18, 94.

(73) S.V. Dorozhkin, Biomatter, 2014, 1, 121. 
Table of Contents

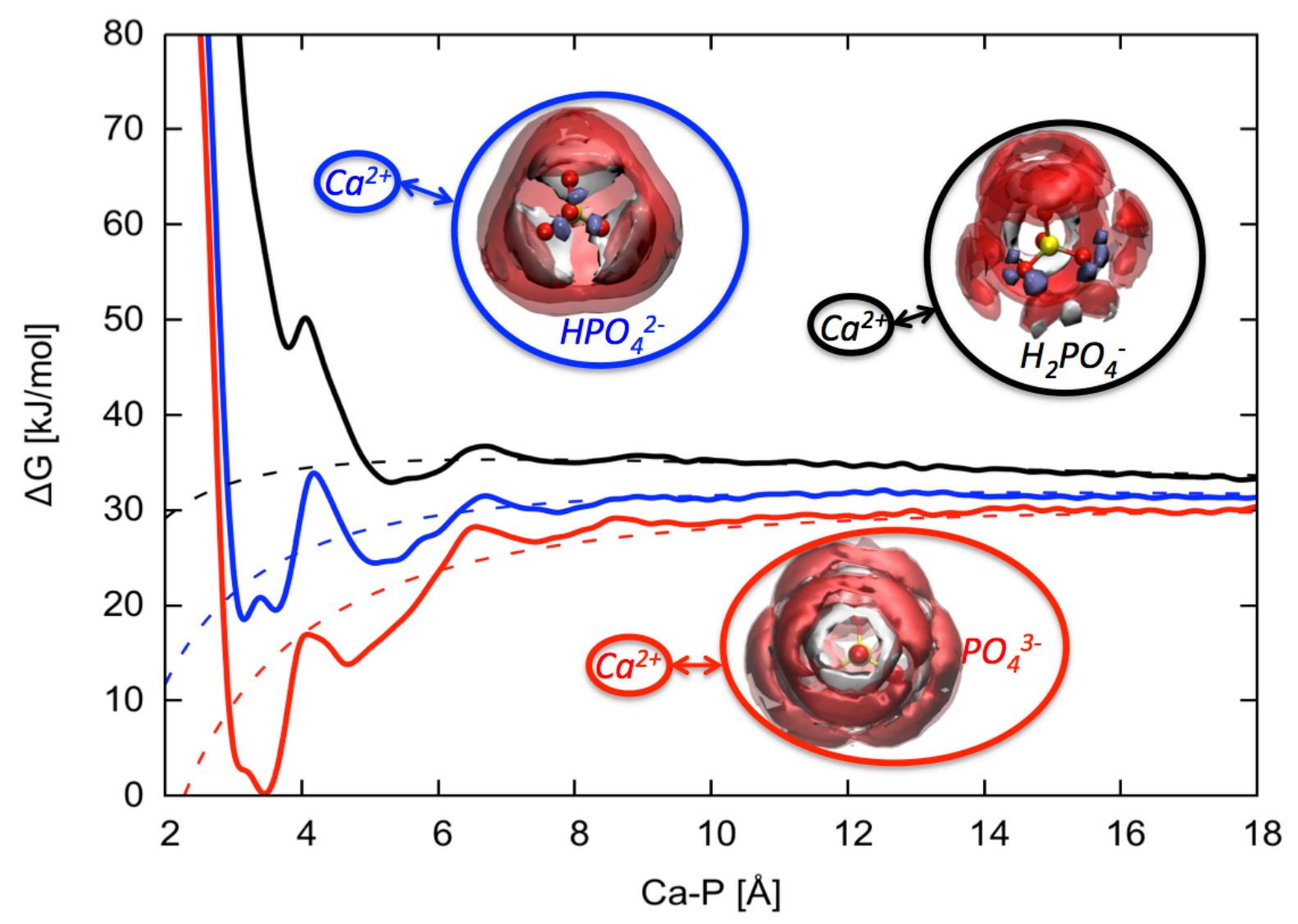



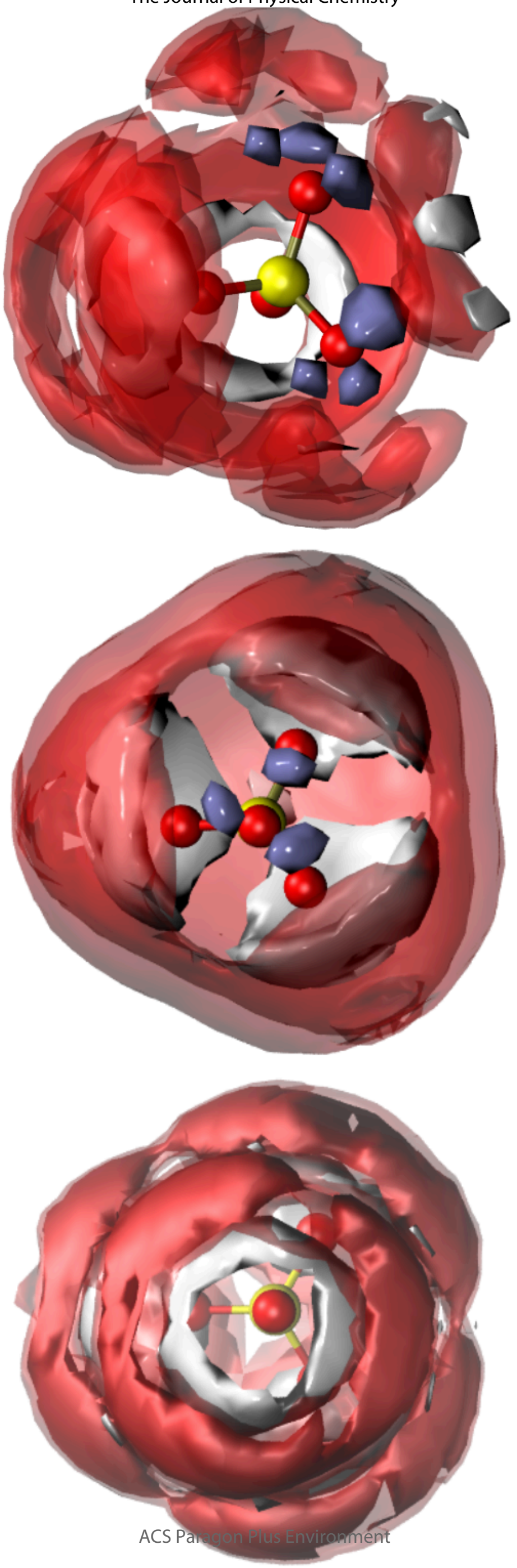
$\begin{array}{lllllllll}1 & \infty & \circ & 8 & \circ & \circ & \circ & \circ & \circ \\ 3 & 1 & 1 & 1 & 1 & 1\end{array}$

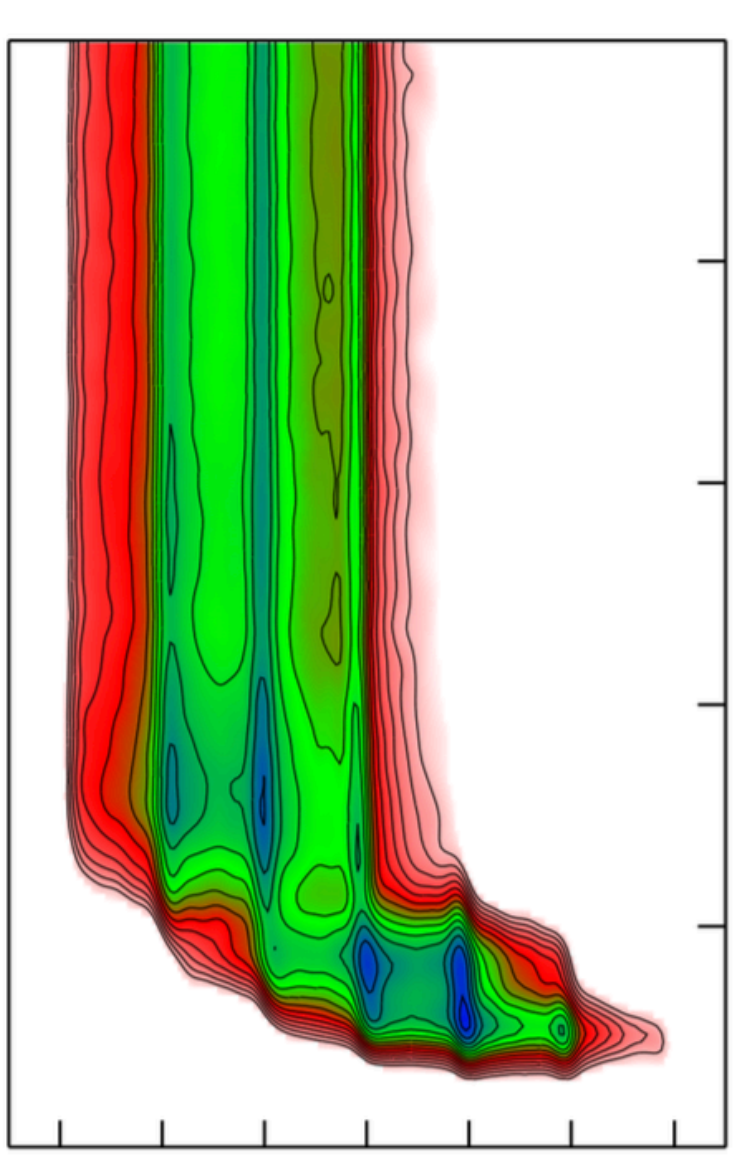

\section{N}
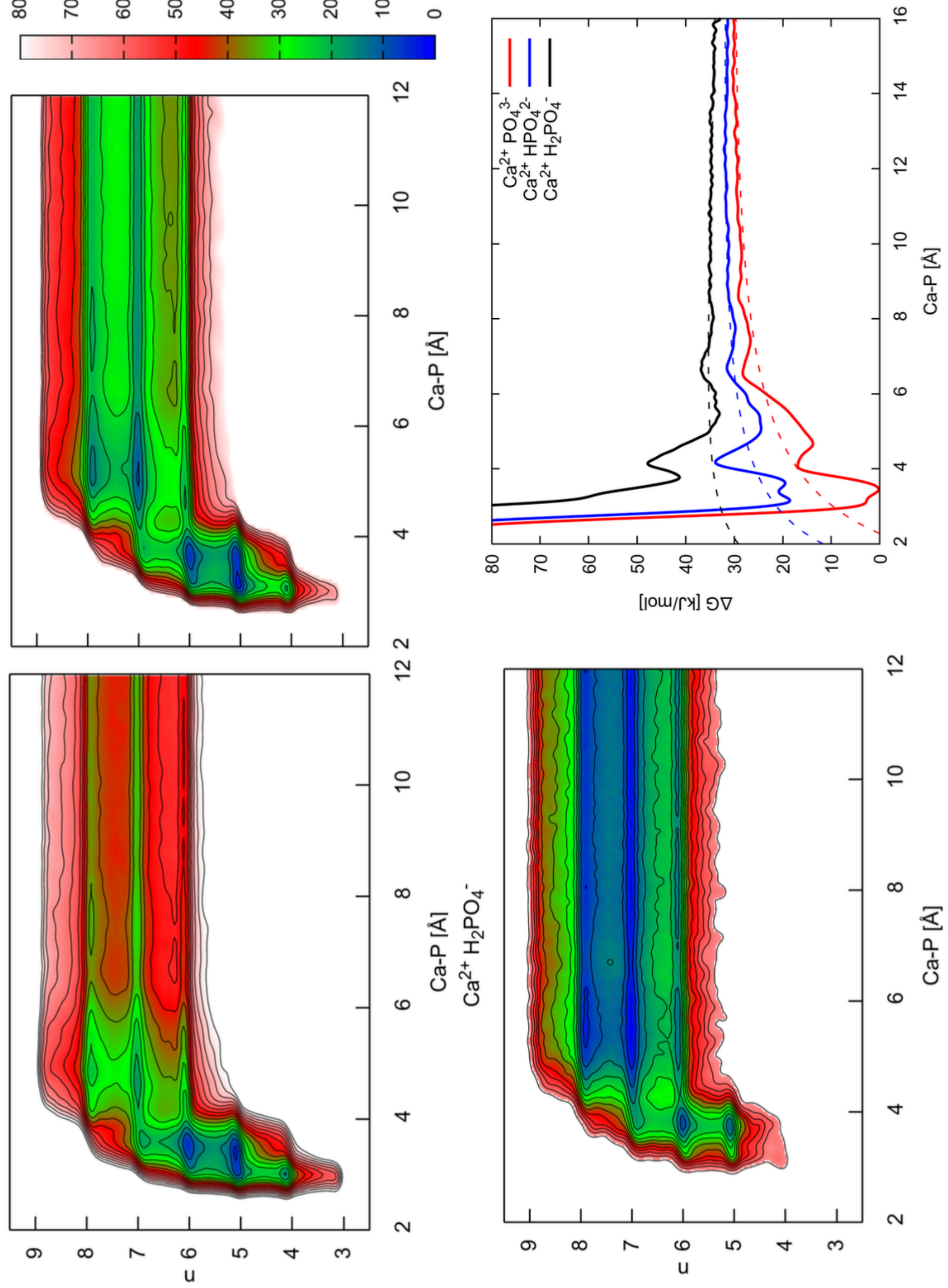

.

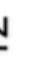

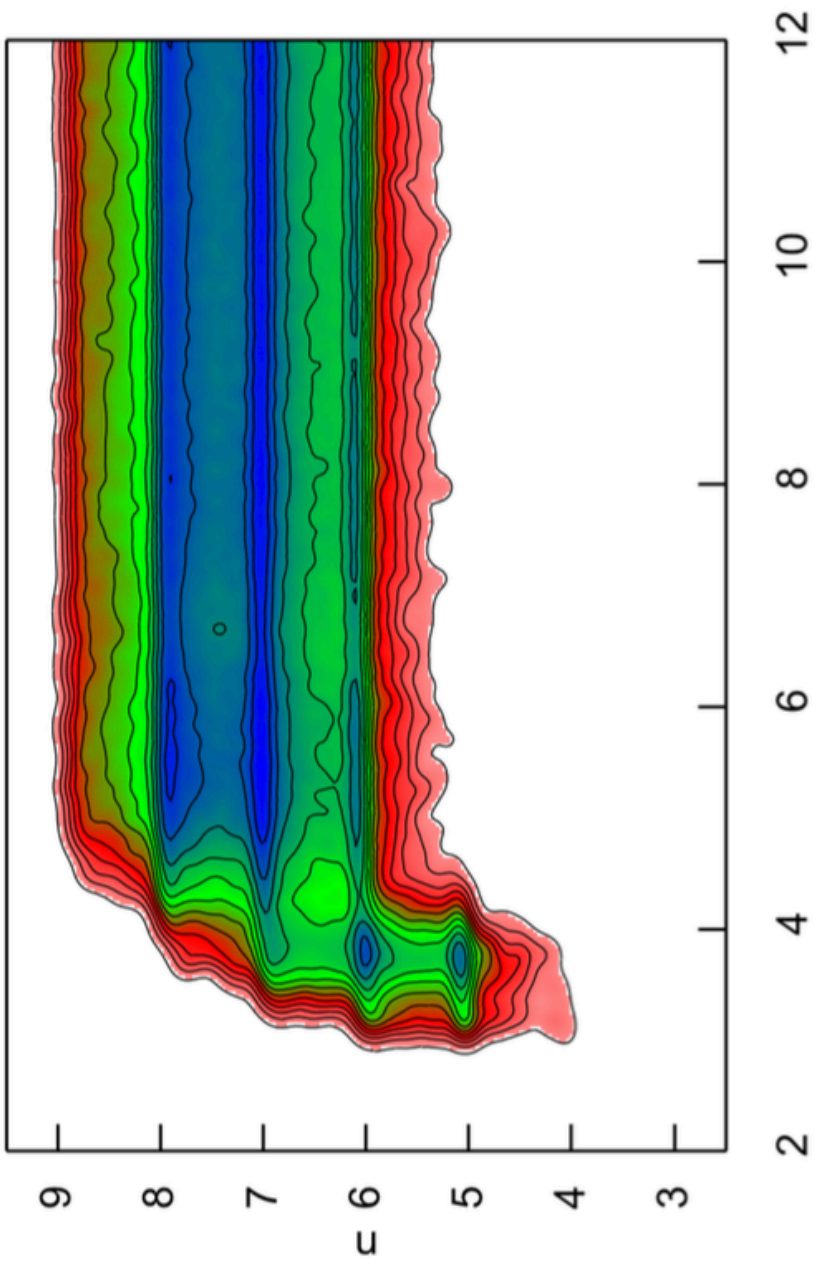

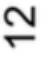

近

லั 


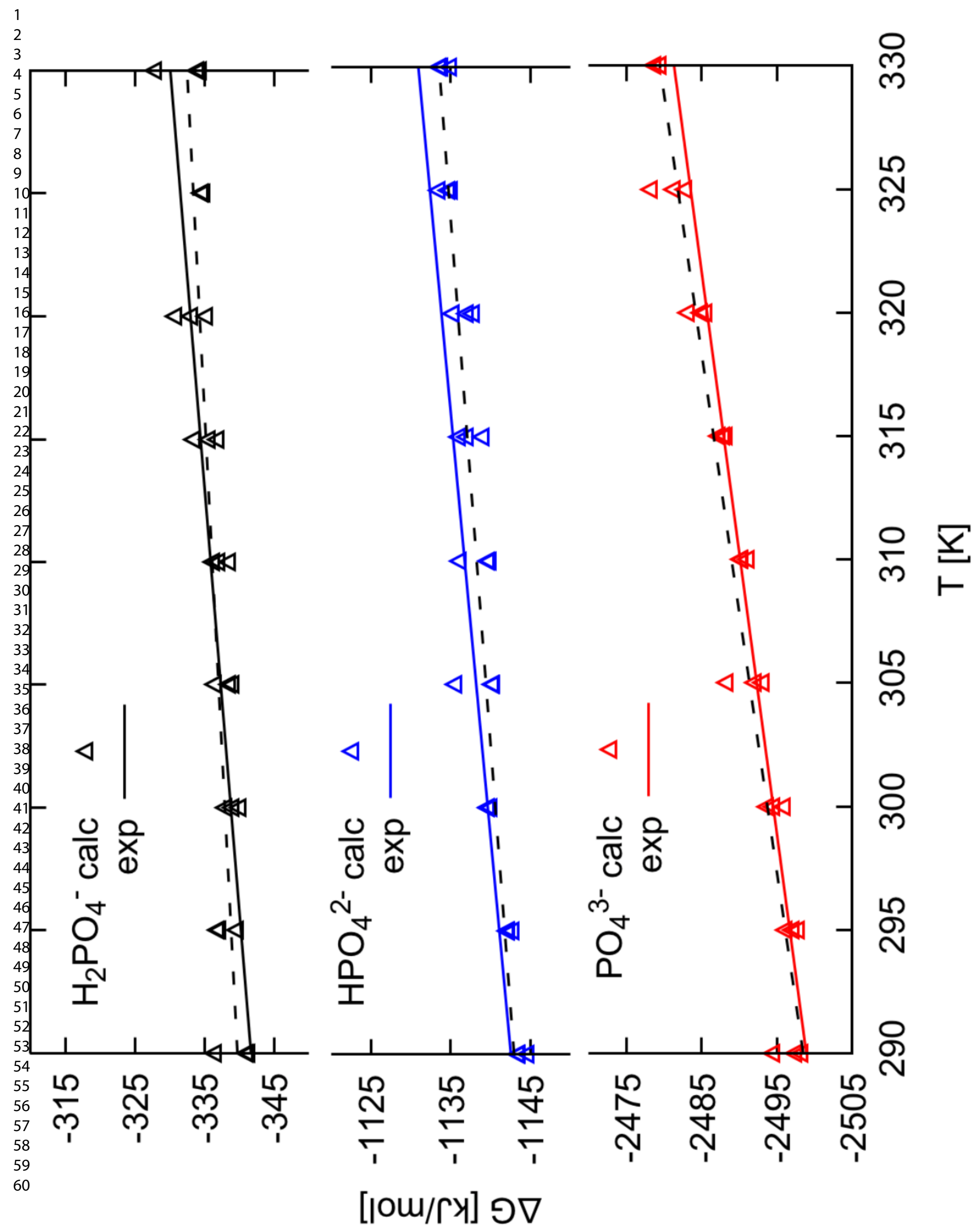




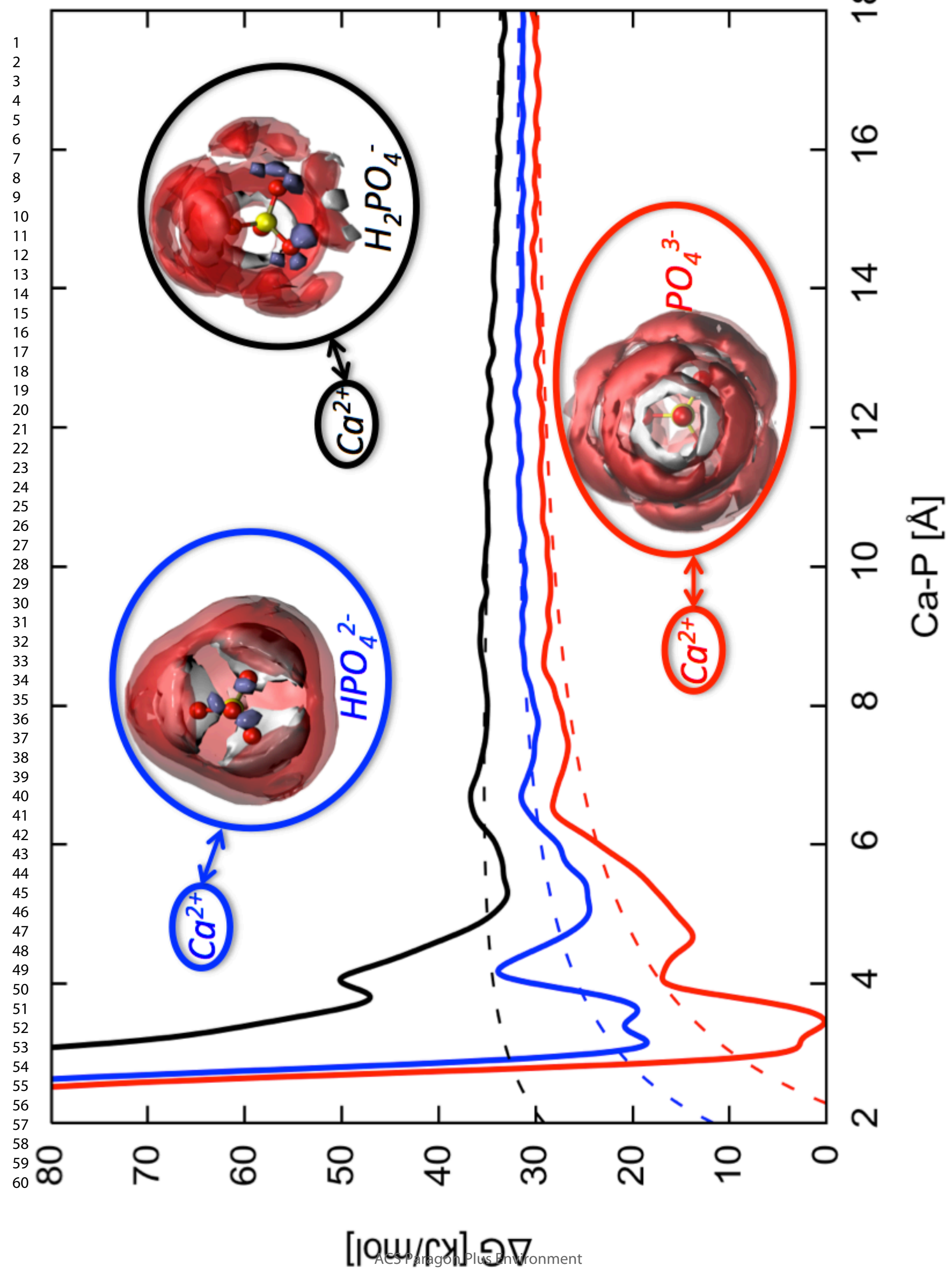

